\title{
ARTICLE
}

\section{Human pharmacokinetics of ginkgo terpene lactones and impact of carboxylation in blood on their platelet-activating factor antagonistic activity}

Xin-wei Liu ${ }^{1,2}$, Jun-ling Yang ${ }^{1}$, Wei Niu ${ }^{1}$, Wei-wei Jia ${ }^{1}$, Olajide E. Olaleye ${ }^{1}$, Qi Wen ${ }^{1}$, Xiao-na Duan ${ }^{1}$, Yü-hong Huang ${ }^{3}$, Feng-qing Wang ${ }^{1}$, Fei-fei $\mathrm{Du}^{1}$, Chen-chun Zhong ${ }^{1}$, Yan-fen $\mathrm{Li}^{3}$, Fang $\mathrm{Xu}^{1}$, Qi Gao ${ }^{4}$, $\mathrm{Li} \mathrm{Li}^{1}$ and Chuan $\mathrm{Li}^{1,2}$

Terpene lactones are a class of bioactive constituents of standardized preparations of Ginkgo biloba leaf extract, extensively used as add-on therapies in patients with ischemic cardiovascular and cerebrovascular diseases. This investigation evaluated human pharmacokinetics of ginkgo terpene lactones and impact of their carboxylation in blood. Human subjects received oral YinXingTongZhi tablet or intravenous ShuXueNing, two standardized ginkgo preparations. Their plasma protein-binding and plateletactivating factor antagonistic activity were assessed in vitro. Their carboxylation was assessed in phosphate-buffered saline (pH 7.4) and in human plasma. After dosing YinXing-TongZhi tablet, ginkgolides $A$ and $B$ and bilobalide exhibited significantly higher systemic exposure levels than ginkgolides $C$ and J; after dosing ShuXueNing, ginkgolides A, B, C, and J exhibited high exposure levels. The compounds' unbound fractions in plasma were $45-92 \%$. Apparent oral bioavailability of ginkgolides $A$ and $B$ was mostly $>100 \%$, while that of ginkgolides $C$ and J was $6-15 \%$. Bilobalide's bioavailability was probably high but lower than that of ginkgolides A/B. Terminal half-lives of ginkgolides A, B, and C (4-7 h) after dosing ShuXueNing were shorter than their respective values (6-13 h) after dosing YinXing-TongZhi tablet. Half-life of bilobalide after dosing the tablet was around $5 \mathrm{~h}$. Terpene lactones were roughly evenly distributed in various body fluids and tissues; glomerular-filtration-based renal excretion was the predominant elimination route for the ginkgolides and a major route for bilobalide. Terpene lactones circulated as trilactones and monocarboxylates. Carboxylation reduced platelet-activating factor antagonistic activity of ginkgolides A, B, and C. Ginkgolide J, bilobalide, and ginkgo flavonoids exhibited no such bioactivity. Collectively, differences in terpene lactones' exposure between the two preparations and influence of their carboxylation in blood should be considered in investigating the relative contributions of terpene lactones to ginkgo preparations' therapeutic effects. The results here will inform rational clinical use of ginkgo preparations.

Keywords: Ginkgo biloba; human pharmacokinetics; renal excretion; terpene lactone; monocarboxylate; platelet-activating factor Acta Pharmacologica Sinica (2018) 39:1935-1946; https://doi.org/10.1038/s41401-018-0086-7

\section{INTRODUCTION}

Extracts of Ginkgo biloba leaves are used worldwide either as botanical drug products or as dietary supplements. The first standardized G. biloba leaf extract was introduced into medical practice by the German physician-pharmacist Dr. Willmar Schwabe III in 1965 for management of insufficiency states of cerebral and peripheral circulation and neurosensory organs [1, 2]. In China, extracts of G. biloba leaves are formulated as tablets and capsules for oral (p.o.) administration and as injection for intravenous (i.v.) administration. These formulations are regulated, by the China Food and Drug Administration (China FDA), as botanical drug products and extensively used as add-on therapies in patients with ischemic cardiovascular and cerebrovascular diseases, such as stable angina pectoris and stroke. Terpene lactones and flavonols are believed to be the two classes of bioactive constituents responsible for the therapeutic effects of $G$. biloba leaf extract formulations [3-5]. The terpene lactones are found exclusively in $G$. biloba trees and comprise the diterpenes ginkgolides A, B, C, and J and the sesquiterpene bilobalide (Fig. 1). The ginkgolides have six five-membered rings (three lactones, two carbocycles, and a tetrahydrofuran ring) and a tert-butyl group; these compounds vary mainly in the number and positions of their hydroxyl groups. Bilobalide has four five-membered rings (three lactones and a carbocycle) and a tert-butyl group. Many terpene lactones are reported to have anti-inflammatory [6, 7], endothelial protective [8,9], cardioprotective [10], antiplatelet [11], and antioxidant properties in cell-based and animal-based studies $[12,13]$. Ginkgolides A, B, and C are also platelet-activating factor (PAF) receptor antagonists $[14,15]$. PAF is a phospholipid mediator that is involved in many cardiovascular pathophysiological processes, such as atherogenesis, ischemia-reperfusion injury of the heart, and cardiac anaphylaxis and shock syndromes [16]. The flavonols are mainly derived from quercetin, kaempferol, and isorhamnetin and are found as monoglycosides, diglycosides, and

\footnotetext{
${ }^{1}$ State Key Laboratory of Drug Research, Shanghai Institute of Materia Medica, Chinese Academy of Sciences, Shanghai 201203 , China; ${ }^{2}$ University of Chinese Academy of Sciences, Shanghai 201203, China; ${ }^{3}$ Second Affiliated Hospital, Tianjin University of Traditional Chinese Medicine, Tianjin 300250, China and ${ }^{4}$ SPH XingLing Science \& Technology Pharmaceutical Co., Ltd., Shanghai 201703, China

Correspondence: Chuan Li (chli@simm.ac.cn) or Li Li (lili00lily@126.com)
}

Received: 4 April 2018 Accepted: 31 May 2018

Published online: 27 July 2018 


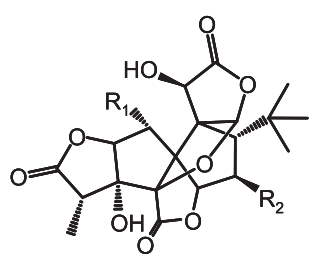

Ginkgolide A; $\mathrm{C}_{20} \mathrm{H}_{24} \mathrm{O}_{9} / \mathrm{MW}: 408 / / \mathbf{R}_{\mathbf{1}}: \mathrm{H}, \mathbf{R}_{\mathbf{2}}: \mathrm{H}$ Ginkgolide B; $\mathrm{C}_{20} \mathrm{H}_{24} \mathrm{O}_{10} / \mathrm{MW}: 424 / / \mathbf{R}_{\mathbf{1}}: \mathrm{OH}, \mathbf{R}_{\mathbf{2}}: \mathrm{H}$ Ginkgolide $\mathrm{C} ; \mathrm{C}_{20} \mathrm{H}_{24} \mathrm{O}_{11} / \mathrm{MW}: 440 / / \mathbf{R}_{\mathbf{1}}: \mathrm{OH}, \mathbf{R}_{\mathbf{2}}: \mathrm{OH}$ Ginkgolide J; $\mathrm{C}_{20} \mathrm{H}_{24} \mathrm{O}_{10} / \mathrm{MW}: 424 / / \mathbf{R}_{\mathbf{1}}: \mathrm{H}, \mathbf{R}_{\mathbf{2}}: \mathrm{OH}$
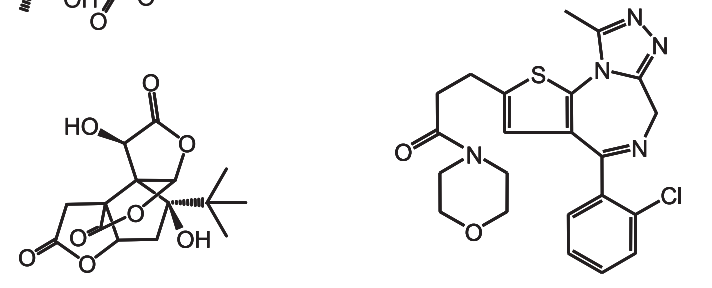

Bilobalide; $\mathrm{C}_{15} \mathrm{H}_{18} \mathrm{O}_{8} / \mathrm{MW}: 326$

WEB 2086; $\mathrm{C}_{22} \mathrm{H}_{22} \mathrm{ClN}_{5} \mathrm{O}_{2} \mathrm{~S} / \mathrm{MW}: 455$

Fig. 1 Chemical structures of ginkgo terpene lactones and WEB2086 (a known PAF antagonist)

triglycosides. Some flavonol glycosides, such as rutin, were also reported to have antiinflammatory [17], endothelial protective [18], and antioxidant properties in cell-based and animal-based studies [19].

To facilitate understanding the link between administration of G. biloba leaf extract and its pharmacological action and identifying the extract's chemical basis responsible for its therapeutic effects, we performed rat-based and cell-based pharmacokinetic studies of GBE50, a standardized G. biloba leaf extract, and ShuXueNing, a ginkgo preparation for i.v. administration $[20,21]$. Among a variety of ginkgo constituents present in dosed GBE50 and ShuXueNing, terpene lactones and flavonols were found to be the major circulating ginkgo compounds (unchanged or metabolized) in rats. After p.o. administration of GBE50, intestinal absorption of unchanged terpene lactones depended mainly on their rates of membrane permeation, while such absorption was poor for unchanged flavonol glycosides. In the colon, the ginkgo flavonol glycosides were deglycosylated, by action of the parasitic microflora, into their absorbable aglycones, which were further conjugated by the host enterohepatic phase II drug metabolizing enzymes before being excreted into bile or entering the systemic circulation. Unlike p.o. administration, i.v. administration of ShuXueNing resulted in unchanged flavonol glycosides as the major circulating forms. Enterohepatic circulation and renal excretion are two factors jointly responsible for significant differences in elimination kinetics between terpene lactones and flavonols in rats. Given that significant interspecies differences in colonic microflora-induced metabolism, biliary excretion, and renal excretion between rats and humans often occur for xenobiotics $[22,23]$, human pharmacokinetic investigations of ginkgo preparations are needed; results of such investigations will inform the design and interpretation of clinical studies of the ginkgo preparations and help ensure pharmacokinetic compatibility for the success of ginkgo-including combination drug therapies. Although some investigators developed assays for measurement of human plasma and urinary concentrations of ginkgo terpene lactones and flavonols over time after p.o. administration of ginkgo preparations [24-27], the compounds' pharmacokinetics in humans have not been systematically investigated $[28,29]$. To this end, a pharmacokinetic investigation of YinXing-TongZhi tablet (GBE50 tablet) and ShuXueNing (ChiCTR-OPN-14005272) was designed and implemented in healthy human subjects. Notably, the structures of ginkgolides in solution are highly $\mathrm{pH}$-dependent and their lactones start to open under the physiologic $\mathrm{pH}$ condition $[30,31]$. Human paraoxonase-1 (PON1) is a calcium-dependent esterase that can hydrolyze lactones, aromatic carboxylic acid esters, and toxic organophosphate compounds [32]. Recently,
Table 1. Content levels and doses of terpene lactones from YinXingTongZhi tablet at the label daily dose 3 tablets/person and from ShuXueNing at the label daily dose $20 \mathrm{~mL}$ injection/person

\begin{tabular}{llllll}
\hline $\begin{array}{l}\text { Terpene } \\
\text { lactone }\end{array}$ & \multicolumn{2}{l}{ YinXing-TongZhi tablet } & & \multicolumn{2}{l}{ ShuXueNing } \\
\cline { 2 - 3 } \cline { 5 - 6 } & $\begin{array}{l}\text { Content } \\
(\mu \mathrm{mol} / \\
\text { tablet })\end{array}$ & $\begin{array}{l}\text { Compound } \\
\text { daily dose } \\
(\mu \mathrm{mol} / \text { person) }\end{array}$ & & $\begin{array}{l}\text { Content } \\
(\mu \mathrm{mol} / \mathrm{L})\end{array}$ & $\begin{array}{l}\text { Compound } \\
\text { daily dose } \\
(\mu \mathrm{mol} / \text { person) }\end{array}$ \\
\hline Ginkgolide A & 3.74 & 11.2 & 152 & 3.04 \\
Ginkgolide B & 1.88 & 5.64 & 112 & 2.25 \\
Ginkgolide C & 1.51 & 4.53 & 132 & 2.65 \\
Ginkgolide J & 0.62 & 1.86 & 68.2 & 1.36 \\
Bilobalide & 6.23 & 18.7 & 6.50 & 0.13 \\
\hline
\end{tabular}

some investigators measured the monocarboxylate forms of ginkgolides A, B, and C in rat and dog plasma samples [33-35]. However, little is known about the influence of PON1 on monocarboxylate-to-trilactone ratios of circulating terpene lactones in humans and the influence of carboxylation (hydrolysis) on biological activities of these ginkgo compounds. This report describes the results of human pharmacokinetics of terpene lactones and impact of carboxylation in blood on their PAF antagonistic activities.

\section{MATERIALS AND METHODS}

Materials and chemicals

YinXing-TongZhi tablet was prepared from the powdered extract of G. biloba leaves GBE50 and each tablet contained not less than $2.4 \mathrm{mg}$ of terpene lactones (consisting of ginkgolides $A, B$, and $C$ and bilobalide) and not less than $9.6 \mathrm{mg}$ of flavonol glycosides (consisting of glycosides of quercetin, kaempferol, and isorhamnetin). The tablet was manufactured by SPH XingLing Science \& Technology Pharmaceutical (Shanghai, China) with a China FDA drug ratification number of Z20060371. ShuXueNing was also prepared from $G$. biloba leaves and each milliliter of injection contained not less than $0.14 \mathrm{mg}$ of terpene lactones (consisting of ginkgolides A, B, and $\mathrm{C}$ ) and not less than $0.84 \mathrm{mg}$ of flavonol glycosides (consisting of glycosides of quercetin, kaempferol, and isorhamnetin). The injection was manufactured by Langzhi Group Wanrong Pharmaceutical (Wanrong, Shanxi Province, China) with a China FDA drug ratification number of Z14021871. Table 1 summarizes daily doses of individual terpene lactones, measured using the assay by Li et al. [20], from YinXing-TongZhi tablet and from ShuXueNing.

Purified ginkgolides A, B, C, and J and bilobalide (purity, >98\%; all in trilactone form) were obtained from Tauto Biotech (Shanghai, China). Major flavonols present in ShuXueNing were isolated and purified from GBE50, while major circulating flavonol metabolites from YinXing-TongZhi tablet were synthesized in-house chemically or enzymatically (details pending publication elsewhere). Sodium heparin, sodium citrate, pentobarbital, ethylenediaminetetraacetic acid (EDTA), calcium chloride $\left(\mathrm{CaCl}_{2}\right)$, and other chemicals were obtained from Sinopharm Chemical Reagent (Shanghai, China). Para-aminohippuric acid, prostaglandin $\mathrm{F}_{2 a}$, estrone-3-sulfate, estradiol-17 $\beta$-D-glucuronide, tetraethylammonium, methotrexate, probenecid, cimetidine, and verapamil were obtained from Sigma-Aldrich (St. Louis, MO, USA). Platelet-activating factor-16 (PAF-16) was purchased from EMD Millipore (Billcrica, MA, USA). HPLC-grade methanol, acetonitrile, formic acid, and ethyl acetate were obtained from Sigma-Aldrich. HPLC-grade water was prepared in-house using a Millipore Milli-Q Integral 3 cabinet water purifying system (Bedford, MA, USA). 
Protocol for collection of drug-free human blood was reviewed and approved by the Ethics Committee for Biomedical Research at Shanghai Institute of Materia Medica (Shanghai, China); the blood samples were centrifuged to prepare blank human plasma. Protocol for the rabbit blood collection was reviewed and approved by the Institutional Animal Care and Use Committee at Shanghai Institute of Materia Medica; male White New Zealand rabbits were obtained from JiaGan Biological Science \& Technology (Shanghai, China).

\section{Human pharmacokinetic studies of YinXing-TongZhi tablet and} ShuXueNing

Protocols for human studies were reviewed and approved by the Ethics Committee of Clinical Investigation at the Second Affiliated Hospital of Tianjin University of Traditional Chinese Medicine (Tianjin, China). The studies were registered in Chinese Clinical Trials Registry (www.chictr.org.cn) with a registration number of ChiCTR-OPN-14005272 and carried out at the National Clinical Research Center of the hospital. A total of 36 healthy volunteers (18 men and 18 women), aged between 23 and 27 years with a body mass index between 19.3 and $25.4 \mathrm{~kg} / \mathrm{m}^{2}$, were recruited and they gave written informed consents to participate in the studies.

In the first study, human subjects were randomly assigned into two groups (three men and three women per group). Human subjects in one group received a single p.o. dose of YinXingTongZhi tablet at 3 tablets/person, the label daily dose of the tablet. Serial blood samples (around $2.5 \mathrm{~mL}$ ) were collected, from an antecubital vein catheter into heparinized vacuum tubes, before and $1,2,3,5,7,8,10,12,13,15,24,29,34,48,58$, and $72 \mathrm{~h}$ after dosing, while serial urine samples were collected before and at $0-3,3-7,7-24,24-48$, and $48-72 \mathrm{~h}$ after dosing. Subjects in the other group received a $2-\mathrm{h}$ i.v. infusion of ShuXueNing at $20 \mathrm{~mL} /$ person, the label daily dose of the injection. Before infusion, $20 \mathrm{~mL}$ of ShuXueNing was diluted in $250 \mathrm{~mL}$ of $5 \%$ glucose injection (GuoYaoZhunZi-H12020021; China Otsuka Pharmaceutical, Tianjin, China). Serial blood samples (around $2.5 \mathrm{~mL}$ ) were collected before and 1, 2 (just before terminating the infusion), 2.17, 2.5, 3, 4, 7, 12, $24,34,48$, and $58 \mathrm{~h}$ after starting infusion, while serial urine samples were collected before and at $0-3,3-7,7-24,24-48$, and $48-72 \mathrm{~h}$ after starting infusion. The blood samples were centrifuged at $2000 \times g$ for $10 \mathrm{~min}$ to obtain the plasma fractions, while urine samples were weighed. All plasma and urine samples were stored at $-70^{\circ} \mathrm{C}$ pending analysis. Both liver and kidney function markers, i.e., serum alanine aminotransferase, aspartate aminotransferase, total protein, albumin/globulin ratio, total bilirubin, direct bilirubin, serum creatinine, and blood urea nitrogen, were monitored in human subjects before dosing and $48 \mathrm{~h}$ after starting i.v. infusion or after p.o. administration.

To obtain stronger pharmacokinetic findings of ginkgo flavonols from YinXing-TongZhi tablet (the results pending publication elsewhere), as well as those of ginkgo terpene lactones, additional 24 human subjects ( 12 men and 12 women) were recruited to receive a dose of YinXing-TongZhi tablet at 9 tablets/person, three times as much as the label daily dose of the tablet. On day 1 , serial blood samples (around $2.5 \mathrm{~mL}$ ) were collected into heparinized vacuum tubes before and 1, 2, 3, 5, 7, 8, 10, 12, 13, 15, 24, 28, and $34 \mathrm{~h}$ after dosing. Meanwhile, urine samples were collected before and at $0-3,3-7,7-24$, and $24-34 \mathrm{~h}$ after dosing. In addition, after a 72-h wash-out period (after dosing on day 1), 12 (six men and six women) of the 24 subjects continued to receive the same dose of YinXing-TongZhi tablets each day for the following 14 days. The time schedule for blood sampling on days 4-16 was before and 2 and $7 \mathrm{~h}$ after daily dosing, whereas the time schedules for blood and urine samplings for dosing on day 17 were the same as those for day 1 . Blood samples were centrifuged at $2000 \times g$ for $10 \mathrm{~min}$ to obtain the plasma fractions, while urine samples were weighed. All plasma and urine samples were stored at $-70^{\circ} \mathrm{C}$ pending analysis. The liver and kidney function markers were monitored on days 1,10 , and 17 before each daily dosing.

Assessment of protein binding of terpene lactones in human plasma

Unbound fractions in human plasma $\left(f_{\mathrm{u}}\right)$ were assessed for ginkgolides A, B, C, and $\mathrm{J}$, and bilobalide using a rapid ultrafiltration method described by Guo et al. [36]. After centrifugation of human blood samples, collected $2 \mathrm{~h}$ after p.o. administration of YinXing-TongZhi tablet (to evaluate $f_{\mathrm{u}}$ of ginkgolides $A$ and $B$ and bilobalide) and just before terminating i.v. infusion of ShuXueNing (to evaluate $f_{\mathrm{u}}$ of ginkgolides A, B, C, and J), $200 \mu \mathrm{L}$ of each resulting plasma fraction was immediately filtered at $13,362 \times g$ and $37^{\circ} \mathrm{C}$ for 3 min using Microcon YM-30 centrifugal filter devices (Millipore, Bedford, MA, USA). The unbound concentrations of the ginkgo terpene lactones in the filtrate (plasma water) and the total (unbound plus bound) concentrations in the pre-filtration plasma sample were measured by liquid chromatography/mass spectrometry, after the samples were treated with $50 \mu \mathrm{L}$ of freshly prepared $20 \mathrm{mmol} / \mathrm{L}$ ascorbic acid- $4 \mathrm{~mol} / \mathrm{L}$ hydrochloric acid solution. Non-specific binding of the ginkgo compounds to the filter membranes was negligible. The $f_{\mathrm{u}}(\%)$ was calculated using the following equation:

$f_{\mathrm{u}}=\left(C_{\mathrm{u}} / C_{\mathrm{t}}\right) \times 100 \%$,

where $C_{u}$ is the unbound concentration $(\mathrm{nmol} / \mathrm{L})$ in the filtrate sample and $C_{\mathrm{t}}$ is the total concentration $(\mathrm{nmol} / \mathrm{L})$ in the associated pre-filtration plasma sample.

Assessment of blood-plasma partition of terpene lactones Freshly collected and heparinized pre-dose blank human blood samples were spiked with ginkgolides $A, B, C$, and $J$ and bilobalide to assess, in triplicate, the blood-to-plasma concentration ratios (B/ $P$ ratios) of ginkgo terpene lactones using method described by Chen et al. [21]. After incubation at $37^{\circ} \mathrm{C}$ for $1 \mathrm{~h}$, the blood samples were centrifuged; the resulting plasma and erythrocyte fractions were analyzed to determine the compound's concentration. The $\mathrm{B} / \mathrm{P}$ ratio was calculated using the following equation:

$\mathrm{B} / \mathrm{P}$ ratio $=\left[\mathrm{H} \times C_{\mathrm{E}}+(1-\mathrm{H}) \times C_{\mathrm{P}}\right] / C_{\mathrm{P}}$,

where $C_{E}$ and $C_{P}$ are concentrations ( $\mathrm{nmol} / \mathrm{L}$ ) of test compound in the erythrocytes and plasma, respectively. The hematocrit value (H) of human blood sample was 0.44 [37].

\section{Cellular transport assays for terpene lactones}

Cell culture and assessment of cellular uptake of ginkgolides $A$, B, C, and J and bilobalide in HEK-293 cells (American Type Culture Collection; Manassas, VA, USA) transiently transfected with human renal uptake transporters were performed using methods described by Jia et al. [38]. Full open reading frames of organic anion transporter (OAT) 1-, OAT2-, OAT3-, OAT4-, organic aniontransporting polypeptide (OATP) 4C1-, organic cation transporter (OCT) 2-, carnitine/organic cation transporter (OCTN) 1-, and multidrug and toxin extrusion protein (MATE) 1-CDNA were synthesized and subcloned into pcDNA $3.1(+)$ expression vectors. The inserts of the pcDNA 3.1(+)-transporter constructs were sequenced and aligned according to the GenBank accession numbers NM_004790, NM_006672, NM_004254, NM_018484, NM_180991, NM_003058, NM_003059, and NM_018242, respectively (www. ncbi.nlm.nih.gov/genbank/). The pcDNA 3.1(+)-transporter constructs and the empty vector were introduced separately into HEK293 cells with Lipofectamine 2000 transfection reagent (Invitrogen, Carlsbad, CA, USA). Before use, the transfected cells (TC) were functionally validated using the positive substrates para-aminohippuric acid (for OAT1), prostaglandin $F_{2 a}$ (OAT2), estrone-3sulfate (OAT3, OAT4, and OATP4C1) and tetraethylammonium 
(OCT2, OCTN1, and MATE1) and using the positive inhibitors probenecid (for OAT1, OAT2, OAT3, OAT4, and OATP4C1), cimetidine (OCT2 and MATE1), and verapamil (OCTN1). Transport studies were carried out in 24-well poly-D-lysine-coated plates with cells $48 \mathrm{~h}$ after transfection. The transport rate in $\mathrm{pmol} / \mathrm{mg}$ protein/min was calculated using the following equation:

Transport $=\left(C_{\mathrm{C}} \times V_{\mathrm{C}}\right) / T / W_{\mathrm{C}}$,

where $C_{C}, V_{C}, T$, and $W_{C}$ represent concentration of test compound in the cellular lysate $(\mu \mathrm{mol} / \mathrm{L})$, volume of the lysate $(\mu \mathrm{L})$, incubation time $(10 \mathrm{~min})$, and measured protein amount in the lysate $(\mathrm{mg})$, respectively. Differential uptake between the TC and the mock cells (MC) was defined as net transport ratio (Transport ${ }_{\mathrm{TC}}$ / Transport $_{M C}$ ratio); a net transport ratio $>3$ suggested a positive result.

Assessment of carboxylation of terpene lactones

Carboxylation of ginkgolides A, B, C, and J and bilobalide were assessed by spiking these compounds in isotonic phosphatebuffered saline ( $\mathrm{pH} 7.4$ ), in blank human plasma ( $\mathrm{pH} 7.4$ ), in EDTApretreated blank human plasma, and in EDTA/CaCl -pretreated blank human plasma and then incubated for $15 \mathrm{~min}$ and $3 \mathrm{~h}$. The incubation samples were analyzed to determine total monocarboxylate form-to-trilactone form ratios of terpene lactones (MC/TL ratio). The final concentrations of EDTA and $\mathrm{CaCl}_{2}$ in the incubation mixtures were 5 and $10 \mathrm{mmol} / \mathrm{L}$, respectively.

\section{Analysis of terpene lactones in biological matrices}

A Thermo Fisher TSQ Quantum mass spectrometer (San Jose, CA, USA), interfaced via an electrospray ionization probe with an Agilent 1290 UHPLC (Waldbronn, Germany), was used to analyze various study samples. Bioanalytical assays for measurement of trilactone (TL)-terpene lactones were modified from the method described by Zhao et al. [39]. In brief, after mixing with $50 \mu \mathrm{L}$ of $20 \mathrm{mmol} / \mathrm{L}$ ascorbic acid-4 mol/L hydrochloric acid solution, the human plasma or urine samples $(50 \mu \mathrm{L})$ were heated at $80^{\circ} \mathrm{C}$ for $30 \mathrm{~min}$ and extracted with $1 \mathrm{~mL}$ of ethyl acetate. The resulting ethyl acetate extracts were reduced under a stream of nitrogen gas and the residue was reconstituted in $50 \mu \mathrm{L}$ of acetonitrile. Chromatographic separation was achieved using a 5- $\mu$ m Agilent Zorbax Eclipase plus $\mathrm{C}_{18}$ column $(50 \times 2.1 \mathrm{~mm}$ i.d.; Santa Clara, CA, USA) with a mobile phase consisting of solvent $A$ (water, containing $1 \mathrm{mmol} / \mathrm{L}$ formic acid) and solvent B (methanol, containing $1 \mathrm{mmol} / \mathrm{L}$ formic acid). The mobile phase was delivered at $0.3 \mathrm{~mL} / \mathrm{min}$ in a gradient manner, i.e., $0-1 \mathrm{~min}$, at $25 \%$ solvent $\mathrm{B}$; $1-3.5 \mathrm{~min}$, from 25 to $98 \%$ solvent $\mathrm{B} ; 3.5-5 \mathrm{~min}$, at $98 \%$ solvent $\mathrm{B}$ and $5.1-7 \mathrm{~min}$, at $25 \%$ solvent $B$. The mass spectrometry parameters were optimized in the negative ion mode; precursorto-product ion pairs used for selected reaction monitoring of TLginkgolides A, B, C, and J and TL-bilobalide were $\mathrm{m} / \mathrm{z} 453 \rightarrow 351$ (the optimal collision energy, $21 \mathrm{eV}), 423 \rightarrow 367(18 \mathrm{eV}), 439 \rightarrow 383$ $(17 \mathrm{eV}), 423 \rightarrow 349(29 \mathrm{eV})$, and $325 \rightarrow 163(21 \mathrm{eV})$, respectively, with a scan time of $0.2 \mathrm{~s}$ for each ion pair. Only eluent flow of liquid chromatography over a period of $1.5-4.5 \mathrm{~min}$ was introduced to the ion source. Matrix-matched calibration curves were constructed for the five analytes using weighted $\left(1 / X^{2}\right)$ linear regressions of the analyte response (peak area; $Y$ ) against the corresponding nominal biosample concentrations of the analytes $(X, \mathrm{nmol} / \mathrm{L})$, which showed good linearity $\left(r^{2}>0.99\right)$; the dynamic concentration ranges were 1.91-980, 0.92-943, 0.44-909, 3.68-943, and 2.40-1227 nmol/L for TL-ginkgolides A, B, C, and $\mathrm{J}$, and TL-bilobalide, respectively. Assay validation was carried out according to the European Medicines Agency Guideline on Bioanalytical Method Validation (2012; www.ema.europa.eu) to demonstrate that the bioanalytical assays were reliable for the intended application. The lower limits of quantification were 0.44 $3.68 \mathrm{nmol} / \mathrm{L}$ for the analytes. The assay's precision and accuracy were $13-19 \%$ and $83-117 \%$, respectively. The coefficients of variation of matrix factors were $1-12 \%$. The stability of analytes under conditions mimicking the analytical process was evaluated: after storage at $24^{\circ} \mathrm{C}$ for $1 \mathrm{~h}$, in ethyl acetate at $24^{\circ} \mathrm{C}$ for $1 \mathrm{~h}$, in reconstitution solvent at $8{ }^{\circ} \mathrm{C}$ for $12 \mathrm{~h}$, and after three freeze-andthaw cycles. The test compounds were stable under the test conditions, with coefficients of variation of -12 to $15 \%$.

A Waters Synapt G2 high-definition time-of-flight mass spectrometer (Manchester, UK), interfaced via a LockSpray source with a Waters Acquity ultra performance liquid chromatographic separation module (Milford, MA, USA), was used to analyze the carboxylation of terpene lactones in human plasma and urine samples and in phosphate-buffered saline ( $\mathrm{pH} 7.4)$. The samples $(50 \mu \mathrm{L})$ were prepared by precipitating with methanol (volumetric precipitant-to-sample ratio of 3), without any acidification. After centrifugation, the supernatants $(3 \mu \mathrm{L})$ were directly applied to the liquid chromatography/mass spectrometry system. Chromatographic separations were achieved using a 1.8- $\mathrm{mm}$ Waters HSS T3 column $(100 \times 2.1 \mathrm{~mm}$ i.d.) with a mobile phase consisting of solvent $A$ (water, containing $1 \mathrm{mmol} / \mathrm{L}$ formic acid) and solvent $B$ (methanol, containing $1 \mathrm{mmol} / \mathrm{L}$ formic acid). The gradient program for delivering the mobile phase at $0.3 \mathrm{~mL} / \mathrm{min}$ was as follows: $0-1.5 \mathrm{~min}$, at $10 \%$ solvent $\mathrm{B} ; 1.5-6 \mathrm{~min}$, from 10 to $60 \%$ solvent $B ; 6-8 \mathrm{~min}$, at $98 \%$ solvent $B ; 8-10 \mathrm{~min}$, at $10 \%$ solvent $B$. The mass spectrometer was operated in the negative ion mode, with a resolution power of around 10,000 . External calibration was performed over a range of $\mathrm{m} / \mathrm{z} 50-1500$ using a $5 \mathrm{mM}$ sodium formate solution at $10 \mu \mathrm{L} / \mathrm{min}$, while mass shifts during acquisition were corrected using leucine encephalin $(\mathrm{m} / \mathrm{z} 554.2615$ for the negative ion mode). Both MC-terpene and TL-terpene lactones were monitored, i.e., $\mathrm{m} / \mathrm{z} 425.1448,441.1397,451.1346,441.1397$, 343.1029, 407.1342, 423.1291, 439.1240, 423.1291, and 325.0923, for MC-ginkgolides A, B, C, and J and MC-bilobalides and TLginkgolides A, B, C, and J, and TL-bilobalide, respectively. Only eluent flow of liquid chromatography over a period of 3.5-6.5 min was introduced to the ion source. Matrix-matched calibration curves of TL-ginkgolides $A, B, C$, and J, and TL-bilobalide were used for quantification of MC-ginkgolides $A, B, C$, and $J$, and $M C$ bilobalides, respectively, as well as for quantification of TLginkgolides A, B, C, and J, and TL-bilobalide, respectively.

\section{Identification of PAF antagonists from circulating ginkgo} compounds

Blood was collected, in citrated vacuum tubes, from the abdominal aorta of the rabbits $(3-4 \mathrm{~kg})$ that were anaesthetized with pentobarbital $(5 \mathrm{mg} / \mathrm{kg}$; i.v.). After centrifugation of the freshly collected rabbit blood $(4 \mathrm{~mL})$ at $200 \times g$ and room temperature for $10 \mathrm{~min}$, the upper layer $(1 \mathrm{~mL})$ was collected, which was platelet-rich rabbit plasma (rabbit PRP; $\mathrm{pH}$ 7.4), and used within $2 \mathrm{~h}$ after centrifugation. The remaining fraction of blood ( $3 \mathrm{~mL}$ ) was centrifuged at $2000 \times g$ and room temperature for $10 \mathrm{~min}$, the upper layer $(0.5 \mathrm{~mL})$ was collected, which was platelet-poor rabbit plasma (rabbit PPP; $\mathrm{pH}$ 7.4). Rabbit PRP and PPP were used for calibration of $0 \%$ platelet aggregation and $100 \%$ platelet aggregation, respectively. Inhibition potencies of test ginkgo compounds (initially dissolved in $1 \mu \mathrm{L}$ dimethyl sulfoxide; TL-ginkgolides A, B, C, and J, TL-bilobalide, unchanged and metabolized ginkgo flavonols) against rabbit platelet aggregation were screened after a 5 -min preincubation of the test compound in $300 \mu \mathrm{L}$ of rabbit PRP at $37^{\circ} \mathrm{C}$ and each test compound's final concentration was $100 \mu \mathrm{mol} / \mathrm{L}$. After adding $10 \mu \mathrm{L}$ of $10 \mathrm{nmol} / \mathrm{L}$ PAF-16, the mixture was further incubated at $800 \mathrm{rpm}$ and $37^{\circ} \mathrm{C}$ for $5 \mathrm{~min}$ and platelet aggregation was then measured on a PRECIL LBY-NJ4 Platelet Aggregometer (Techlink Biomedical; Beijing, China). For a compound demonstrating $>50 \%$ inhibition, half maximal inhibitory concentration $\left(I C_{50}\right)$ was determined using concentrations ranging from 0.125 to 32 $\mu \mathrm{mol} / \mathrm{L}$ and calculated by linear regression analysis of log 
concentration vs. the respective percentage inhibition. During incubation in rabbit PRP, transformation of TL-terpene lactones into their respective $M C$ forms was negligible. Impact of carboxylation on the PAF antagonistic activities of ginkgolides A, $B$, and $C$ was determined by incubating these test compounds in human plasma ( $\mathrm{pH} 7.4$ ) and in isotonic phosphate-buffered saline ( $\mathrm{pH}$ 7.4) for $3 \mathrm{~h}$ before platelet aggregation measurement. Inhibition potencies of these three ginkgolides against the PAF16 -induced platelet aggregation were assessed in $300 \mu \mathrm{L}$ of rabbit PRP using the preceding method, except for the final test concentrations $0.3-100 \mu \mathrm{mol} / \mathrm{L}$.

Data processing

Pharmacokinetic parameters were estimated by noncompartmental analysis using Thermo Kinetica software (version 5.0; Philadelphia, PA, USA). The maximum concentration $\left(C_{\max }\right)$ and the time taken to achieve the maximum concentration $\left(T_{\max }\right)$ after p.o. dose were obtained directly from the data without any interpolation. The area under the concentration-time curve up to the last time point of measurement $\left(A \cup C_{0-t}\right)$ was calculated using the trapezoidal rule and that from zero to infinity $\left(A \cup C_{0-\infty}\right)$ was generated by extrapolating the $\mathrm{AUC}_{0-\mathrm{t}}$ to infinity using the $k_{\mathrm{e}}$ (the elimination rate constant) and the last measured concentration. The total plasma clearance $\left(\mathrm{CL}_{\text {tot, }}\right)$ was estimated by dividing the i.v. dose by the $A U C_{0-\infty}$ i the total blood clearance $\left(\mathrm{CL}_{\text {tot,b }}\right)$ was estimated by dividing the $\mathrm{CL}_{\text {tot,p }}$ by the $\mathrm{B} / \mathrm{P}$ ratio. The distribution volume at steady state $\left(V_{\mathrm{SS}}\right)$ was estimated by multiplying the $\mathrm{CL}_{\text {tot,p }}$ by the mean residence time. The $t_{1 / 2}$ was calculated using the relationship $0.693 / k_{\mathrm{e}}$. When expressed as $F_{(\mathrm{AUC})}$, absolute oral bioavailability was estimated by dividing the $A \cup C_{0-\infty, \text { p.o. }} /$ Dose $_{\text {p.o. }}$. by the $\mathrm{AUC}_{0-\infty, \mathrm{i} . \mathrm{V}} / \mathrm{Dose}_{\mathrm{i} . \mathrm{v} .} ;$ when expressed as $F_{(\mathrm{Cum} . \mathrm{Ae}-\mathrm{U}) \text {, it was }}$ estimated by dividing the Cum. $A_{\mathrm{e}-\mathrm{u} \text {, o.o }} /$ Dose $_{\mathrm{p.o}}$ by the Cum.A $A_{\mathrm{e}-\mathrm{u} \text {,i.v. }}$ / Dose $_{\text {i.v. }}$. Here, Cum. $A_{\mathrm{e}-\mathrm{U}}$ is the cumulative amount excreted into urine. The accumulation ratio $\left(R_{\mathrm{ac}}\right)$ was calculated to indicate the extent of accumulation during multiple doses of YinXing-TongZhi tablets using $A U C_{0-\infty(\text { Day } 14)} / A U C_{0-\infty(D a y 1)}$. The fraction of dose excreted into urine $\left(f_{\mathrm{e}-\mathrm{u}}\right)$ was established using the relationship Cum. $A_{\mathrm{e}-\mathrm{u}} /$ Dose. A reported human glomerular filtration rate (GFR), $0.11 \mathrm{~L} / \mathrm{h} / \mathrm{kg}$ [37], was used to calculate the $\mathrm{CL}_{\mathrm{R}} /\left(\mathrm{GFR} \times f_{\mathrm{u}}\right)$. Compounds with $\mathrm{CL}_{\mathrm{R}} /\left(\mathrm{GFR} \times f_{\mathrm{u}}\right)$ data of $<0.8$, around 1.0 , and $>1.5$ indicated renal excretion involving tubular reabsorption, predominantly via glomerular filtration, and involving transportermediated tubular secretion, respectively $[40,41]$. GraFit software (version 5; Surrey, UK) was used to determine the $I C_{50}$ values. All data are expressed as the mean \pm standard deviation. Statistical analysis was performed using IBM SPSS Statistics software (version 19.0; IBM, Chicago, IL, USA). A $P$ value $<0.05$ was considered statistically significant.

\section{RESULTS}

Plasma pharmacokinetics of terpene lactones after dosing YinXing-TongZhi tablet or ShuXueNing in human subjects During the study periods, no serious adverse event was observed in human subjects who received p.o. YinXing-TongZhi tablet or i.v. ShuXueNing; the subjects' liver and kidney function indicators were all within the normal ranges. Figure 2 shows mean plasma concentrations of terpene lactones over time after a 2-h i.v. infusion of ShuXueNing at $20 \mathrm{~mL} /$ person (the label daily dose of the injection) and after a single p.o. dose of YinXing-TongZhi tablets at 3 (the label daily dose of the tablets) and 9 tablets/ person. Tables 2 and 3 summarize the pharmacokinetic parameters of terpene lactones in the human subjects. All the data shown in this subsection were based on measurement of TLginkgo terpene lactones in human plasma samples.

After dosing ShuXueNing, ginkgolides $A$ and $C$ exhibited significantly higher total (unbound plus bound) levels of systemic exposure $\left(C_{\max }\right.$ and $\left.A \cup C_{0-\infty}\right)$ than ginkgolides $\mathrm{B}$ and $\mathrm{J}(P<0.05)$.
The differences in exposure levels largely correlated with differences in the compounds' doses from the injection. Neither $C_{\max }$ nor $\mathrm{AUC}_{0-\infty}$ of these ginkgo compounds exhibited significant gender differences $(P=0.43-0.91)$, after correcting the compound doses for the body weight of subject. Inter-individual differences in $C_{\max }$ and $\mathrm{AUC}_{0-\infty}$ corrected by the body weight of subject, were not large, as indicated by their relative standard deviations (7.4-18.8\%). These ginkgolides exhibited two-compartment pharmacokinetics with terminal half-lives $\left(t_{1 / 2,7 \mathrm{~h}-\mathrm{t}}\right)$ of $3.9-7.7 \mathrm{~h}$, except for ginkgolide $J$ with too low plasma concentrations for estimation

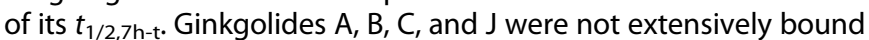
in human plasma, with $f_{\mathrm{u}}$ values of $45-92 \%$. Gender differences in $V_{\mathrm{SS}}$ or $\mathrm{CL}_{\text {tot,p }}$ were not significant $(P=0.16-0.96)$. The $V_{\mathrm{SS}}$ of ginkgolides $B, A, J$, and $C$, in ascending order, were $0.9-2.7$ times as large as the human volume of total body water (0.6 L/kg [37]), suggesting these ginkgo compounds were roughly evenly distributed in various body fluids and tissues. Ginkgolides were slowly cleared from the systemic circulation. This is indicated by their $\mathrm{CL}_{\text {tot,b }}$ values, which were only $3-8 \%$ of human cardiac output (4.8 L/h/kg [37]). Levels of systemic exposure to bilobalide were quite low, due to its low compound dose from ShuXueNing (Table 1).

Unlike in ShuXueNing, bilobalide was the most abundant terpene lactone in YinXing-TongZhi tablet (Table 1). Meanwhile, the doses of ginkgolides from the tablet (at the label daily dose) were greater than the respective doses from ShuXueNing (at the label daily dose). After p.o. dosing YinXing-TongZhi tablet, bilobalide, ginkgolides $A$, and B exhibited significantly higher total levels of systemic exposure than ginkgolides $C$ and $\mathrm{J}(P<$ 0.05). Neither their $C_{\max }$ nor $A \cup C_{0-\infty}$ exhibited significant gender differences $(P=0.42-0.96)$, after correcting the compound doses for the body weight of subject (Tables 2 and 3). Inter-individual differences in $C_{\max }$ and $\mathrm{AUC}_{\mathrm{O}-\infty}$, corrected for the body weight of subject, after dosing YinXing-TongZhi tablets were also not large for ginkgolides $A$ and $B$, as indicated by the relative standard deviations $6-21 \%$, while such differences were relatively large for ginkgolides C and J (31-58\%). Comparison of the exposure data between the two doses of YinXing-TongZhi tablet given to the human subjects, i.e., 3 and 9 tablets/person, suggested that both $C_{\max }$ and $\mathrm{AUC}_{0-\infty}$ of ginkgo terpene lactones increased mostly by 2.6-4.1 times as the tablet dose increased. The $C_{\max }$ and $A U C_{0-\infty}$ of ginkgolides $A$ and $B$ after dosing YinXing-TongZhi tablet (at the label daily dose) were greater than the respective values of these compounds after dosing ShuXueNing (at the label daily dose). Despite their similar chemical structures, ginkgolides $A$ and $B$ exhibited higher absolute oral bioavailability ( $\left.F_{(A \cup C)}, 99-165 \%\right)$ than ginkgolides $C$ and $J(6-15 \%)$. Such $F_{(A \cup C)}$ value was not available for bilobalide, because its plasma concentrations were too low after dosing ShuXueNing. Dose-corrected $A_{U} C_{0-\infty}$ values of bilobalide were around $50 \%$ of the respective values of coexisting ginkgolide A. During multiple dosing of YinXing-TongZhi tablet at 9 tablets/person for 14 consecutive days, accumulations of circulating ginkgo terpene lactones were negligible, as indicated by their accumulation ratios $\left(R_{\mathrm{ac}}\right)$ shown in Table 3 . Pharmacokinetics of terpene lactones on day 17 in human subjects who received repeated p.o. doses of YinXing-TongZhi tablet daily at 9 tablets/person are summarized in Supplementary Information Table S1.

Renal excretion of terpene lactones after dosing YinXing-TongZhi tablet or ShuXueNing in human subjects

After dosing YinXing-TongZhi tablet, ginkgolides A and B exhibited $f_{\mathrm{e}-\mathrm{U}}$ values around 10 times as great as such values of ginkgolides $C$ and J (Table 2); these inter-compound differences were in line with the differences in the oral bioavailability $F_{(A \cup C)}$ among the compounds. However, after dosing i.v. ShuXueNing, ginkgolides $\mathrm{A}, \mathrm{B}, \mathrm{C}$, and $\mathrm{J}$ all exhibited very large $f_{\mathrm{e}-\mathrm{U}}$ values (Table 2), suggesting that renal excretion was the predominant 

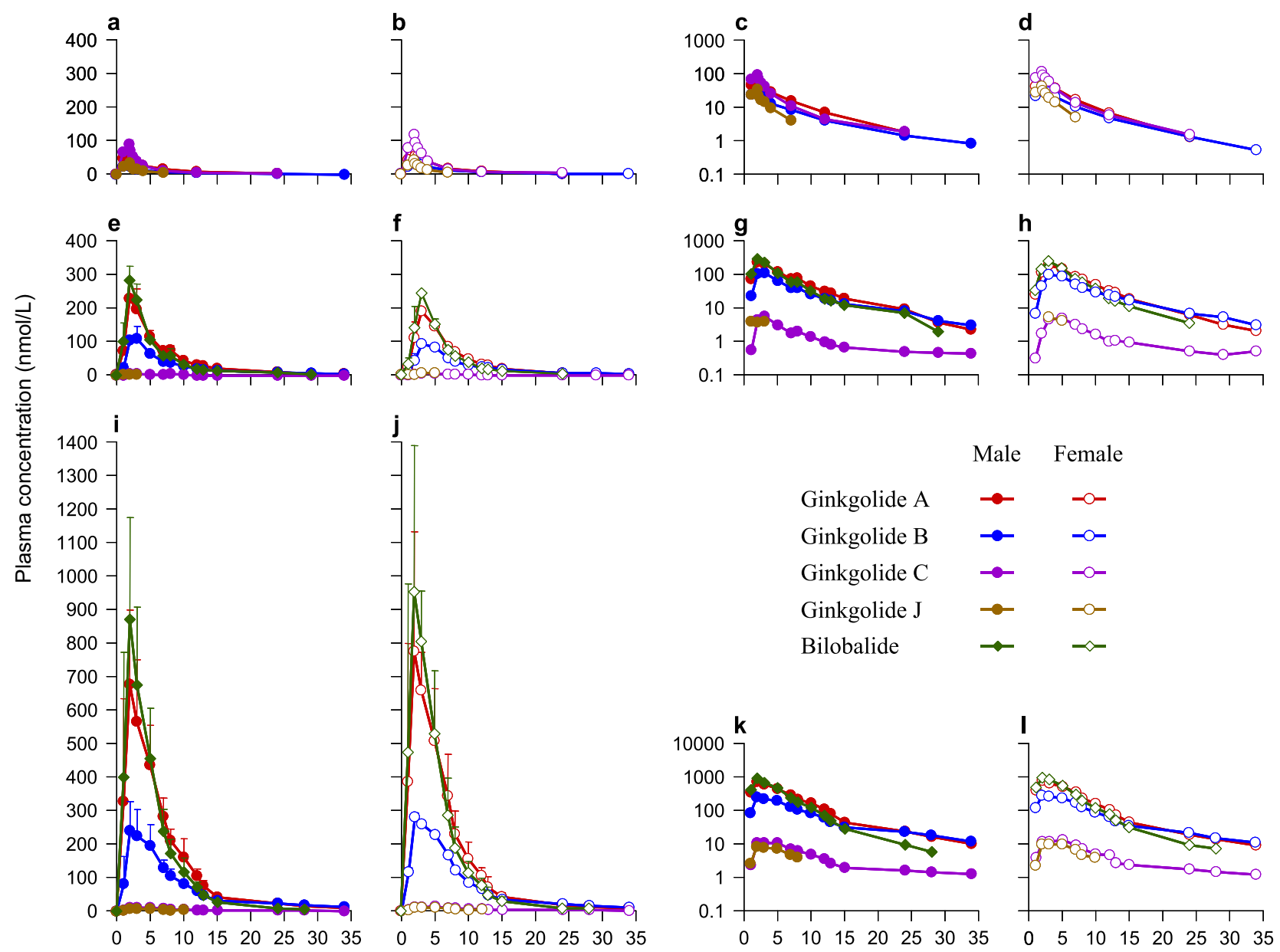

Time (h)

Fig. 2 Plasma concentrations of ginkgo terpene lactones over time after a 2-h i.v. infusion of ShuXueNing at $20 \mathrm{~mL} / \mathrm{person}$ (the label daily dose of the injection; a-d), a p.o. dose of YinXing-TongZhi tablet at 3 tablets/person (the label daily dose of the tablet; $\mathbf{e}-\mathbf{h}$ ), and a p.o. dose of YinXing-TongZhi tablet at 9 tablets/person (i-I) in human subjects

elimination route responsible for their systemic clearance. Bilobalide, after dosing YinXing-TongZhi tablet, exhibited a moderate $f_{\mathrm{e}-\mathrm{u}}$ value, which was around one-third of the values of ginkgolides $A$ and $B$ and around three times as much as such values of ginkgolides $C$ and $J$. The $C L_{R}$ values of ginkgolides $A, B, C$, and $\mathrm{J}$ and bilobalide after dosing YinXing-TongZhi tablet or ShuXueNing were 0.9-1.8 times as much as the respective products of human GFR and the compounds' $f_{\mathrm{u}}$, suggesting that the renal excretion of these ginkgo compounds was based predominantly on glomerular filtration. As shown in Table 4, human renal uptake transporters did not exhibit any transport activity for terpene lactones, except for OAT4 exhibiting a net transport ratio slightly greater than 3 for ginkgolide $C$. Like plasma $\mathrm{AUC}_{0-\infty}$, urinary Cum. $A_{\mathrm{e}-U}$ can be used to estimate absolute oral bioavailability of ginkgolides A, B, C, and J, i.e., $F_{(\text {Cum.Ae-U); }}$ significant inter-compound differences were observed, i.e., the $F_{\text {(Cum.Ae-U) }}$ values of ginkgolides $A$ and $B$ being substantially larger than those of ginkgolides $C$ and J (Tables 2 and 3). Unlike $F_{(A \cup C)}$, the $F_{\text {(Cum.Ae-U) }}$ values of both ginkgolides $A$ and $B$ were $<100 \%$. It is worth mentioning that all the data shown in this subsection were based on measurement of TL-ginkgo terpene lactones in human urine samples.

Carboxylation of terpene lactones in human blood Human plasma and urine samples exhibiting high concentrations of terpene lactones after dosing YinXing-TongZhi tablet or
ShuXueNing were further analyzed to determine the compounds' carboxylated forms, as well as associated MC/TL ratios. As shown in Fig. 3, one to three monocarboxylate forms of ginkgolides $A, B$, $\mathrm{C}$, and $\mathrm{J}$ and bilobalide were detected in the plasma samples $(\mathrm{pH}$ 7.4) with MC/TL ratios of $1.7-2.4,0.4-0.5,0.3-0.9,1.0-2.3$, and $0.5-1.6$, respectively. In the urine samples ( $\mathrm{pH} 5.8-7.4)$, such $\mathrm{MC} / \mathrm{TL}$ ratios were $0.7-1.5,0.1-0.3,0.1-0.2,0.6$, and 0.2 , respectively, which were lower than those of respective compounds for plasma samples. Neither the dicarboxylate nor the tricarboxylate form was detected for these terpene lactones in these plasma or urine samples. In vitro studies were performed to compare the MC/TL ratios of terpene lactones in isotonic phosphate-buffered saline $(\mathrm{pH} 7.4)$ with the respective ratios in human plasma ( $\mathrm{pH} 7.4)$. As shown in Fig. 4, MC/TL ratios of ginkgolides $A, B, C$, and $J$ and bilobalide in human plasma were higher than the respective ratios in the saline; all the ratios increased with the incubation time. In addition, adding EDTA into human plasma resulted in decreased $\mathrm{MC} / \mathrm{TL}$ ratios of terpene lactones; further adding calcium chloride into human plasma did not reverse the effects of EDTA.

Antagonistic activities of ginkgo compounds on PAF-16-induced platelet aggregation and impact of ginkgolides carboxylation in plasma

The test ginkgo compounds were terpene lactones and flavonoids, unchanged and metabolized (the detailed flavonoids' pharmacokinetics and disposition pending publication elsewhere). 
Table 2. Pharmacokinetics of terpene lactones in human subjects who received a single 2-h i.v. infusion of ShuXueNing at $20 \mathrm{~mL}$ injection/person (the label daily dose of the injection) and in those who received a single p.o. dose of YinXing-TongZhi tablet at 3 tablets/person (the label daily dose of the tablet)

\begin{tabular}{lllll}
\hline $\begin{array}{l}\text { Pharmacokinetic } \\
\text { parameter }\end{array}$ & \multicolumn{2}{l}{$\begin{array}{l}\text { Oral YinXing-TongZhi } \\
\text { tablet }\end{array}$} & \multicolumn{2}{l}{$\begin{array}{l}\text { Intravenous } \\
\text { ShuXueNing }\end{array}$} \\
\cline { 2 - 3 } \cline { 5 - 5 } & $\begin{array}{l}\text { Male } \\
(n=3)\end{array}$ & $\begin{array}{l}\text { Female } \\
(n=3)\end{array}$ & $\begin{array}{l}\text { Male } \\
(n=3)\end{array}$ & $\begin{array}{l}\text { Female } \\
(n=3)\end{array}$ \\
\hline
\end{tabular}

Ginkgolide A (11.2 $\mu \mathrm{mol} /$ person from 3 YinXing-TongZhi tablet; $3.0 \mu \mathrm{mol} /$ person from $20 \mathrm{~mL}$ ShuXueNing)

\begin{tabular}{|c|c|c|c|c|}
\hline$C_{\max }(\mathrm{nmol} / \mathrm{L})$ & $225 \pm 51$ & $189 \pm 11$ & $65 \pm 7$ & $76 \pm 14$ \\
\hline $\mathrm{AUC}_{0-\infty}(\mathrm{h} \mathrm{nmol} / \mathrm{L})$ & $\begin{array}{l}1389 \pm \\
143\end{array}$ & $1306 \pm 120$ & $328 \pm 60$ & $353 \pm 41$ \\
\hline$F_{\text {(AUC) }}(\%)$ & $98.8 \pm 6.0$ & & - & \\
\hline$f_{\mathrm{u}}(\%)$ & $67.5 \pm 4.9$ & & $76.3 \pm 10.8$ & \\
\hline$t_{1 / 2,3-7 \mathrm{~h}}(\mathrm{~h})$ & $3.3 \pm 0.8$ & & - & \\
\hline$t_{1 / 2,2-4 \mathrm{~h}}(\mathrm{~h})$ & - & & $2.0 \pm 0.3$ & \\
\hline$t_{1 / 2,7 \mathrm{~h}-\mathrm{t}}(\mathrm{h})$ & $6.3 \pm 1.7$ & & $5.2 \pm 1.0$ & \\
\hline$V_{\mathrm{SS}}(\mathrm{L} / \mathrm{kg})$ & - & & $0.94 \pm 0.14$ & \\
\hline $\mathrm{CL}_{\text {tot,p }}(\mathrm{L} / \mathrm{h} / \mathrm{kg})$ & - & & $0.14 \pm 0.02$ & \\
\hline $\mathrm{CL}_{\text {tot, } \mathrm{b}}(\mathrm{L} / \mathrm{h} / \mathrm{kg})$ & - & & $0.16 \pm 0.02$ & \\
\hline $\begin{array}{l}\text { Cum. } A_{\mathrm{e}-U, 0-72 \mathrm{~h}} \\
(\mu \mathrm{mol})\end{array}$ & $9.2 \pm 0.4$ & $8.8 \pm 0.8$ & $2.6 \pm 0.2$ & $3.1 \pm 0.3$ \\
\hline $\mathrm{CL}_{\mathrm{R}}(\mathrm{L} / \mathrm{h} / \mathrm{kg})$ & $0.11 \pm 0.01$ & & $0.14 \pm 0.03$ & \\
\hline $\mathrm{CL}_{\mathrm{R}} /\left(\mathrm{GFR} \times f_{\mathrm{u}}\right)$ & $1.55 \pm 0.14$ & & $1.65 \pm 0.38$ & \\
\hline$f_{\mathrm{e}-\mathrm{U}}(\%)$ & $80.2 \pm 5.3$ & & $93.7 \pm 10.8$ & \\
\hline$F_{(\text {Cum.Ae-U) }}(\%)$ & $85.6 \pm 5.6$ & & - & \\
\hline
\end{tabular}

Ginkgolide B $(5.6 \mu \mathrm{mol} /$ person from 3 YinXing-TongZhi tablet; $2.2 \mu \mathrm{mol} /$ person from $20 \mathrm{~mL}$ ShuXueNing)

\begin{tabular}{|c|c|c|c|c|}
\hline$C_{\max }(\mathrm{nmol} / \mathrm{L})$ & $113 \pm 30$ & $93.2 \pm 6.0$ & $31.4 \pm 3.3$ & $40.3 \pm 7.9$ \\
\hline $\mathrm{AUC}_{0-\infty}(\mathrm{h} \mathrm{nmol} / \mathrm{L})$ & $807 \pm 71$ & $811 \pm 77$ & $186 \pm 31$ & $218 \pm 31$ \\
\hline$F_{(\mathrm{AUC})}(\%)$ & $148 \pm 8$ & & - & \\
\hline$f_{\mathrm{u}}(\%)$ & $46.9 \pm 6.3$ & & $45.0 \pm 7.9$ & \\
\hline$t_{1 / 2,3-7 \mathrm{~h}}(\mathrm{~h})$ & $3.8 \pm 1.1$ & & - & \\
\hline$t_{1 / 2,2-4 \mathrm{~h}}(\mathrm{~h})$ & - & & $1.8 \pm 0.4$ & \\
\hline$t_{1 / 2,7 \mathrm{~h}-\mathrm{t}}(\mathrm{h})$ & $8.0 \pm 0.5$ & & $7.1 \pm 1.3$ & \\
\hline$V_{\text {SS }}(\mathrm{L} / \mathrm{kg})$ & - & & $1.59 \pm 0.31$ & \\
\hline $\mathrm{CL}_{\text {tot,p }}(\mathrm{L} / \mathrm{h} / \mathrm{kg})$ & - & & $0.18 \pm 0.03$ & \\
\hline $\mathrm{CL}_{\text {tot,b}}(\mathrm{L} / \mathrm{h} / \mathrm{kg})$ & - & & $0.21 \pm 0.03$ & \\
\hline $\begin{array}{l}\text { Cum. } A_{\mathrm{e}-U, 0-72 \mathrm{~h}} \\
(\mu \mathrm{mol})\end{array}$ & $3.8 \pm 0.4$ & $4.0 \pm 0.3$ & $1.4 \pm 0.2$ & $1.9 \pm 0.1$ \\
\hline $\mathrm{CL}_{\mathrm{R}}(\mathrm{L} / \mathrm{h} / \mathrm{kg})$ & $0.09 \pm 0.01$ & & $0.14 \pm 0.03$ & \\
\hline $\mathrm{CL}_{\mathrm{R}} /\left(\mathrm{GFR} \times f_{\mathrm{u}}\right)$ & $1.65 \pm 0.12$ & & $2.76 \pm 0.67$ & \\
\hline$f_{\mathrm{e}-\mathrm{u}}(\%)$ & $69.1 \pm 5.3$ & & $73.6 \pm 11.6$ & \\
\hline$F_{(\text {Cum.Ae-U) }}(\%)$ & $94.0 \pm 7.3$ & & - & \\
\hline \multicolumn{5}{|c|}{$\begin{array}{l}\text { Ginkgolide C ( } 4.5 \mu \text { mol/person from } 3 \text { YinXing-TongZhi tablet; } 2.7 \mu \mathrm{mol} / \\
\text { person from } 20 \mathrm{~mL} \text { ShuXueNing) }\end{array}$} \\
\hline$C_{\max }(\mathrm{nmol} / \mathrm{L})$ & $\begin{array}{l}7.16 \pm \\
4.31\end{array}$ & $4.82 \pm 0.96$ & $90.2 \pm 11.0$ & $117 \pm 19$ \\
\hline$A \cup C_{0-\infty}(\mathrm{h} \mathrm{nmol} / \mathrm{L})$ & $\begin{array}{l}43.8 \pm \\
12.2\end{array}$ & $52.0 \pm 15.1$ & $314 \pm 56$ & $410 \pm 66$ \\
\hline$F_{(\mathrm{AUC})}(\%)$ & $6.2 \pm 3.4$ & & - & \\
\hline$f_{\mathrm{u}}(\%)$ & - & & $87.6 \pm 8.5$ & \\
\hline$t_{1 / 2,3-7 \mathrm{~h}}(\mathrm{~h})$ & $4.1 \pm 1.8$ & & - & \\
\hline$t_{1 / 2,2-4 \mathrm{~h}}(\mathrm{~h})$ & - & & $1.3 \pm 0.3$ & \\
\hline$t_{1 / 2,7 \mathrm{~h}-\mathrm{t}}(\mathrm{h})$ & $6.8 \pm 2.7$ & & $4.0 \pm 1.5$ & \\
\hline$V_{\mathrm{SS}}(\mathrm{L} / \mathrm{kg})$ & - & & $0.54 \pm 0.04$ & \\
\hline
\end{tabular}

\begin{tabular}{|c|c|c|c|c|}
\hline \multicolumn{5}{|l|}{ Table 2 continued } \\
\hline \multirow[t]{2}{*}{$\begin{array}{l}\text { Pharmacokinetic } \\
\text { parameter }\end{array}$} & \multicolumn{2}{|c|}{$\begin{array}{l}\text { Oral YinXing-TongZhi } \\
\text { tablet }\end{array}$} & \multicolumn{2}{|c|}{$\begin{array}{l}\text { Intravenous } \\
\text { ShuXueNing }\end{array}$} \\
\hline & $\begin{array}{l}\text { Male } \\
(n=3)\end{array}$ & $\begin{array}{l}\text { Female } \\
(n=3)\end{array}$ & $\begin{array}{l}\text { Male } \\
(n=3)\end{array}$ & $\begin{array}{l}\text { Female } \\
(n=3)\end{array}$ \\
\hline $\mathrm{CL}_{\text {tot,p }}(\mathrm{L} / \mathrm{h} / \mathrm{kg})$ & - & & $0.12 \pm 0.02$ & \\
\hline $\mathrm{CL}_{\text {tot,b }}(\mathrm{L} / \mathrm{h} / \mathrm{kg})$ & - & & $0.25 \pm 0.04$ & \\
\hline $\begin{array}{l}\text { Cum. } A_{\mathrm{e}-\mathrm{U}, 0-72 \mathrm{~h}} \\
(\mu \mathrm{mol})\end{array}$ & $\begin{array}{l}0.22 \pm \\
0.03\end{array}$ & $0.34 \pm 0.04$ & $2.0 \pm 0.1$ & $2.6 \pm 0.1$ \\
\hline $\mathrm{CL}_{\mathrm{R}}(\mathrm{L} / \mathrm{h} / \mathrm{kg})$ & $0.11 \pm 0.04$ & & $0.11 \pm 0.02$ & \\
\hline $\mathrm{CL}_{\mathrm{R}} /\left(\mathrm{GFR} \times f_{\mathrm{u}}\right)$ & $1.18 \pm 0.36$ & & $1.12 \pm 0.21$ & \\
\hline$f_{\mathrm{e}-\mathrm{u}}(\%)$ & $6.2 \pm 1.6$ & & $87.7 \pm 11.5$ & \\
\hline$F_{(\text {Cum.Ae-U) }}(\%)$ & $7.1 \pm 1.8$ & & - & \\
\hline \multicolumn{5}{|c|}{$\begin{array}{l}\text { Ginkgolide J ( } 1.9 \mu \text { mol/person from } 3 \text { YinXing-TongZhi tablet; } 1.4 \mu \mathrm{mol} / \\
\text { person from } 20 \mathrm{~mL} \text { ShuXueNing) }\end{array}$} \\
\hline$C_{\max }(\mathrm{nmol} / \mathrm{L})$ & $\begin{array}{l}4.23 \pm \\
0.72\end{array}$ & $5.01 \pm 0.15$ & $33.6 \pm 5.0$ & $41.0 \pm 7.0$ \\
\hline$A \cup C_{0-5 h}(h \mathrm{nmol} / \mathrm{L})$ & $\begin{array}{l}15.9 \pm \\
13.7\end{array}$ & $13.5 \pm 5.3$ & - & - \\
\hline $\mathrm{AUC}_{0-7 \mathrm{~h}}(\mathrm{~h} \mathrm{nmol} / \mathrm{L})$ & - & - & $89.6 \pm 12.0$ & $116 \pm 7$ \\
\hline $\mathrm{AUC}_{0-\infty}(\mathrm{h} \mathrm{nmol} / \mathrm{L})$ & - & - & $102 \pm 14$ & $130 \pm 7$ \\
\hline$F_{(\mathrm{AUC})}(\%)$ & $8.5 \pm 5.0$ & & - & \\
\hline$f_{\mathrm{u}}(\%)$ & - & & $91.5 \pm 6.9$ & \\
\hline$t_{1 / 2,2-4 \mathrm{~h}}(\mathrm{~h})$ & - & & $1.1 \pm 0.3$ & \\
\hline$V_{\mathrm{SS}}(\mathrm{L} / \mathrm{kg})$ & - & & $0.67 \pm 0.09$ & \\
\hline $\mathrm{CL}_{\text {tot,p }}(\mathrm{L} / \mathrm{h} / \mathrm{kg})$ & - & & $0.19 \pm 0.01$ & \\
\hline $\mathrm{CL}_{\text {tot,b}}(\mathrm{L} / \mathrm{h} / \mathrm{kg})$ & - & & $0.40 \pm 0.02$ & \\
\hline $\begin{array}{l}\text { Cum. } A_{\mathrm{e}-\mathrm{U}, 0-72 \mathrm{~h}} \\
(\mu \mathrm{mol})\end{array}$ & $\begin{array}{l}0.15 \pm \\
0.01\end{array}$ & $0.20 \pm 0.03$ & $1.1 \pm 0.1$ & $1.2 \pm 0.0$ \\
\hline $\mathrm{CL}_{\mathrm{R}}(\mathrm{L} / \mathrm{h} / \mathrm{kg})$ & $0.26 \pm 0.12$ & & $0.18 \pm 0.02$ & \\
\hline $\mathrm{CL}_{\mathrm{R}} /\left(\mathrm{GFR} \times f_{\mathrm{u}}\right)$ & $2.55 \pm 1.21$ & & $1.75 \pm 0.21$ & \\
\hline$f_{\mathrm{e}-\mathrm{u}}(\%)$ & $9.4 \pm 2.1$ & & $83.7 \pm 7.9$ & \\
\hline$F_{(\text {Cum.Ae-U) }}(\%)$ & $11.2 \pm 2.5$ & & - & \\
\hline \multicolumn{5}{|c|}{$\begin{array}{l}\text { Bilobalide ( } 18.7 \mu \mathrm{mol} / \text { person from } 3 \text { YinXing-TongZhi tablet; } 0.1 \mu \mathrm{mol} / \text { persor } \\
\text { from } 20 \mathrm{~mL} \text { ShuXueNing) }\end{array}$} \\
\hline$C_{\max }(\mathrm{nmol} / \mathrm{L})$ & $282 \pm 42$ & $241 \pm 5$ & - & - \\
\hline $\mathrm{AUC}_{0-\infty}(\mathrm{h} \mathrm{nmol} / \mathrm{L})$ & $1290 \pm 70$ & $1240 \pm 96$ & - & - \\
\hline$f_{\mathrm{u}}(\%)$ & $75.0 \pm 6.4$ & & & \\
\hline$t_{1 / 2,3-7 \mathrm{~h}}(\mathrm{~h})$ & $2.2 \pm 0.3$ & & - & \\
\hline$t_{1 / 2,7 \mathrm{~h}-\mathrm{t}}(\mathrm{h})$ & $4.7 \pm 0.5$ & & $\longrightarrow$ & \\
\hline$V_{S S} / F(\mathrm{~L} / \mathrm{kg})$ & $1.50 \pm 0.14$ & & $\longrightarrow$ & \\
\hline $\mathrm{CL}_{\text {tot, }, \mathrm{p}} / F(\mathrm{~L} / \mathrm{h} / \mathrm{kg})$ & $0.25 \pm 0.02$ & & & \\
\hline $\begin{array}{l}\text { Cum. } A_{\mathrm{e}-\mathrm{U}, 0-72 \mathrm{~h}} \\
(\mu \mathrm{mol})\end{array}$ & $5.5 \pm 0.8$ & $5.4 \pm 0.4$ & - & - \\
\hline $\mathrm{CL}_{\mathrm{R}}(\mathrm{L} / \mathrm{h} / \mathrm{kg})$ & $0.07 \pm 0.01$ & & - & \\
\hline $\mathrm{CL}_{\mathrm{R}} /\left(\mathrm{GFR} \times f_{\mathrm{u}}\right)$ & $0.90 \pm 0.13$ & & & \\
\hline$f_{\mathrm{e}-\mathrm{U}}(\%)$ & $29.3 \pm 3.2$ & & 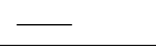 & \\
\hline \multicolumn{5}{|c|}{ 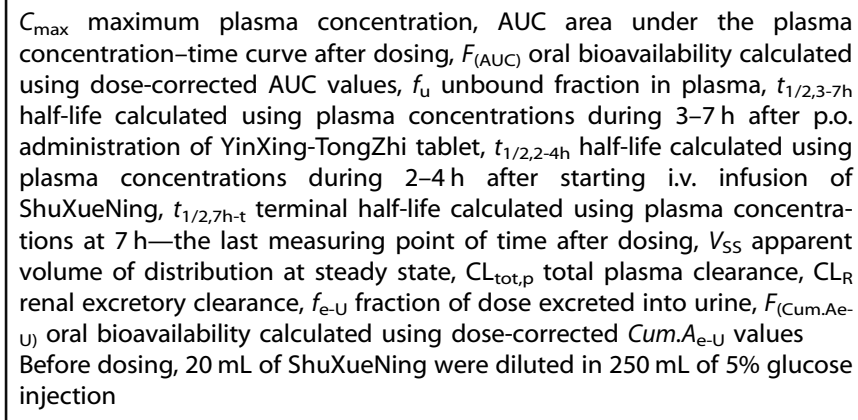 } \\
\hline
\end{tabular}


Table 3. Pharmacokinetics of terpene lactones in human subjects who received a single p.o. dose of YinXing-TongZhi tablet at 9 tablets/person (three times as much as the label daily dose of the tablet)

\begin{tabular}{|c|c|c|}
\hline \multirow[t]{2}{*}{ Pharmacokinetic parameter } & \multicolumn{2}{|c|}{ Oral YinXing-TongZhi tablet } \\
\hline & Male $(n=12)$ & Female $(n=12)$ \\
\hline \multicolumn{3}{|c|}{ Ginkgolide A (33.7 $\mu \mathrm{mol} /$ person from 9 YinXing-TongZhi tablets) } \\
\hline$C_{\max }(\mathrm{nmol} / \mathrm{L})$ & $772 \pm 112$ & $910 \pm 198$ \\
\hline $\mathrm{AUC}_{0-\infty}(\mathrm{h} \mathrm{nmol} / \mathrm{L})$ & $4626 \pm 597$ & $5076 \pm 864$ \\
\hline$F_{(\mathrm{AUC})}(\%)$ & $122 \pm 15$ & $117 \pm 18$ \\
\hline$f_{\mathrm{u}}(\%)$ & $70.1 \pm 8.2$ & $78.7 \pm 12.4$ \\
\hline$R_{\mathrm{ac}}$ & $1.14 \pm 0.12$ & $1.04 \pm 0.27$ \\
\hline$t_{1 / 2,3-7 \mathrm{~h}}(\mathrm{~h})$ & $3.5 \pm 0.8$ & $3.5 \pm 0.4$ \\
\hline$t_{1 / 2,7-34 \mathrm{~h}}(\mathrm{~h})$ & $9.1 \pm 2.6$ & $7.6 \pm 1.6$ \\
\hline Cum. $A_{\mathrm{e}-\mathrm{U}, 0-34 \mathrm{~h}}(\mu \mathrm{mol})$ & $22.8 \pm 8.0$ & $21.2 \pm 3.8$ \\
\hline $\mathrm{CL}_{\mathrm{R}}(\mathrm{L} / \mathrm{h} / \mathrm{kg})$ & $0.08 \pm 0.02$ & $0.08 \pm 0.02$ \\
\hline $\mathrm{CL}_{\mathrm{R}} /\left(\mathrm{GFR} \times f_{\mathrm{u}}\right)$ & $1.02 \pm 0.30$ & $0.91 \pm 0.25$ \\
\hline$f_{\mathrm{e}-\mathrm{U}}(\%)$ & $67.7 \pm 23.8$ & $63.1 \pm 11.4$ \\
\hline$F_{(\text {Cum.Ae-U) }}(\%)$ & $72.2 \pm 25.4$ & $67.3 \pm 12.2$ \\
\hline \multicolumn{3}{|c|}{ Ginkgolide B (16.9 $\mu$ mol/person from 9 YinXing-TongZhi tablets) } \\
\hline$C_{\max }(\mathrm{nmol} / \mathrm{L})$ & $284 \pm 47$ & $344 \pm 77$ \\
\hline$A \cup C_{0-\infty}(\mathrm{h} \mathrm{nmol} / \mathrm{L})$ & $2411 \pm 357$ & $2585 \pm 343$ \\
\hline$F_{(\mathrm{AUC})}(\%)$ & $165 \pm 26$ & $154 \pm 20$ \\
\hline$f_{\mathrm{u}}(\%)$ & $49.4 \pm 9.5$ & $54.5 \pm 8.3$ \\
\hline$R_{\mathrm{ac}}$ & $1.24 \pm 0.17$ & $1.19 \pm 0.29$ \\
\hline$t_{1 / 2,3-7 \mathrm{~h}}(\mathrm{~h})$ & $4.7 \pm 1.4$ & $5.3 \pm 1.5$ \\
\hline$t_{1 / 2,7-34 \mathrm{~h}}(\mathrm{~h})$ & $12.6 \pm 2.1$ & $10.7 \pm 1.8$ \\
\hline Cum. $A_{\mathrm{e}-\mathrm{U}, 0-34 \mathrm{~h}}(\mu \mathrm{mol})$ & $12.7 \pm 3.6$ & $9.8 \pm 2.5$ \\
\hline $\mathrm{CL}_{\mathrm{R}}(\mathrm{L} / \mathrm{h} / \mathrm{kg})$ & $0.09 \pm 0.03$ & $0.07 \pm 0.02$ \\
\hline $\mathrm{CL}_{\mathrm{R}} /\left(\mathrm{GFR} \times f_{\mathrm{u}}\right)$ & $1.69 \pm 0.48$ & $1.24 \pm 0.35$ \\
\hline$f_{\mathrm{e}-\mathrm{u}}(\%)$ & $67.4 \pm 12.9$ & $58.1 \pm 14.5$ \\
\hline$F_{(\text {Cum.Ae-U) }}(\%)$ & $91.6 \pm 17.5$ & $78.9 \pm 19.7$ \\
\hline \multicolumn{3}{|c|}{ Ginkgolide C (13.6 $\mu \mathrm{mol} /$ person from 9 YinXing-TongZhi tablets) } \\
\hline$C_{\max }(\mathrm{nmol} / \mathrm{L})$ & $13.6 \pm 3.8$ & $17.2 \pm 6.6$ \\
\hline$A \cup C_{0-\infty}(\mathrm{h} \mathrm{nmol} / \mathrm{L})$ & $160 \pm 44$ & $164 \pm 37$ \\
\hline$F_{(\mathrm{AUC})}(\%)$ & $9.3 \pm 2.3$ & $7.9 \pm 1.7$ \\
\hline$f_{\mathrm{u}}(\%)$ & - & - \\
\hline$R_{\mathrm{ac}}$ & $1.21 \pm 0.16$ & $1.20 \pm 0.40$ \\
\hline$t_{1 / 2,3-7 \mathrm{~h}}(\mathrm{~h})$ & $4.0 \pm 1.1$ & $4.9 \pm 0.6$ \\
\hline$t_{1 / 2,7-34 \mathrm{~h}}(\mathrm{~h})$ & $12.1 \pm 3.9$ & $10.6 \pm 1.8$ \\
\hline Cum. $A_{\mathrm{e}-\mathrm{U}, 0-34 \mathrm{~h}}(\mu \mathrm{mol})$ & $0.50 \pm 0.18$ & $0.51 \pm 0.15$ \\
\hline $\mathrm{CL}_{\mathrm{R}}(\mathrm{L} / \mathrm{h} / \mathrm{kg})$ & $0.07 \pm 0.02$ & $0.07 \pm 0.02$ \\
\hline $\mathrm{CL}_{\mathrm{R}} /\left(\mathrm{GFR} \times f_{\mathrm{u}}\right)$ & $0.69 \pm 0.21$ & $0.71 \pm 0.20$ \\
\hline$f_{\mathrm{e}-\mathrm{U}}(\%)$ & $3.7 \pm 1.3$ & $3.7 \pm 1.1$ \\
\hline$F_{(\text {Cum.Ae-U) }}(\%)$ & $4.2 \pm 1.5$ & $4.2 \pm 1.3$ \\
\hline \multicolumn{3}{|c|}{ Ginkgolide J (5.6 $\mu$ mol/person from 9 YinXing-TongZhi tablets) } \\
\hline$C_{\max }(\mathrm{nmol} / \mathrm{L})$ & $11.4 \pm 3.3$ & $13.6 \pm 5.3$ \\
\hline $\mathrm{AUC}_{0-\infty}(\mathrm{h} \mathrm{nmol} / \mathrm{L})$ & $69.4 \pm 8.5$ & $80.2 \pm 19.3$ \\
\hline$F_{(\mathrm{AUC})}(\%)$ & $13.6 \pm 4.5$ & $14.6 \pm 3.6$ \\
\hline$f_{\mathrm{u}}(\%)$ & - & - \\
\hline$R_{\mathrm{ac}}$ & $1.00 \pm 0.33$ & $0.94 \pm 0.41$ \\
\hline$t_{1 / 2,3-7 \mathrm{~h}}(\mathrm{~h})$ & $3.7 \pm 1.7$ & $3.7 \pm 1.4$ \\
\hline Cum. $A_{\mathrm{e}-\mathrm{U}, 0-34 \mathrm{~h}}(\mu \mathrm{mol})$ & $0.44 \pm 0.12$ & $0.43 \pm 0.14$ \\
\hline $\mathrm{CL}_{\mathrm{R}}(\mathrm{L} / \mathrm{h} / \mathrm{kg})$ & $0.15 \pm 0.04$ & $0.13 \pm 0.04$ \\
\hline $\mathrm{CL}_{\mathrm{R}} /\left(\mathrm{GFR} \times f_{\mathrm{u}}\right)$ & $1.48 \pm 0.37$ & $1.30 \pm 0.36$ \\
\hline$f_{\mathrm{e}-\mathrm{u}}(\%)$ & $7.9 \pm 2.1$ & $7.7 \pm 2.5$ \\
\hline
\end{tabular}

\begin{tabular}{|c|c|c|}
\hline \multirow[t]{2}{*}{ Pharmacokinetic parameter } & \multicolumn{2}{|c|}{ Oral YinXing-TongZhi tablet } \\
\hline & Male $(n=12)$ & Female $(n=12)$ \\
\hline$F_{(\text {(Cum.Ae-U) }}(\%)$ & $9.4 \pm 2.5$ & $9.2 \pm 3.0$ \\
\hline \multicolumn{3}{|c|}{ Bilobalide (56.0 $\mu \mathrm{mol} /$ person from 9 YinXing-TongZhi tablets) } \\
\hline$C_{\max }(\mathrm{nmol} / \mathrm{L})$ & $987 \pm 169$ & $1119 \pm 247$ \\
\hline$A \cup C_{0-\infty}(\mathrm{h} \mathrm{nmol} / \mathrm{L})$ & $4369 \pm 599$ & $4967 \pm 856$ \\
\hline$f_{\mathrm{u}}(\%)$ & $61.8 \pm 8.9$ & $68.2 \pm 12.8$ \\
\hline$R_{\mathrm{ac}}$ & $1.05 \pm 0.13$ & $0.98 \pm 0.25$ \\
\hline$t_{1 / 2,3-7 \mathrm{~h}}(\mathrm{~h})$ & $2.5 \pm 0.5$ & $2.4 \pm 0.3$ \\
\hline$t_{1 / 2,7-34 h}(\mathrm{~h})$ & $4.8 \pm 1.1$ & $4.4 \pm 0.9$ \\
\hline Cum. $A_{\mathrm{e}-\mathrm{U}, 0-34 \mathrm{~h}}(\mu \mathrm{mol})$ & $18.8 \pm 2.7$ & $20.1 \pm 3.2$ \\
\hline $\mathrm{CL}_{\mathrm{R}}(\mathrm{L} / \mathrm{h} / \mathrm{kg})$ & $0.07 \pm 0.01$ & $0.08 \pm 0.02$ \\
\hline $\mathrm{CL}_{\mathrm{R}} /\left(\mathrm{GFR} \times f_{\mathrm{u}}\right)$ & $1.01 \pm 0.17$ & $1.02 \pm 0.32$ \\
\hline$f_{\mathrm{e}-\mathrm{U}}(\%)$ & $33.6 \pm 4.9$ & $35.9 \pm 5.6$ \\
\hline \multicolumn{3}{|c|}{$\begin{array}{l}C_{\max } \text { maximum plasma concentration, AUC area under the plasma } \\
\text { concentration-time curve after dosing, } F_{(\mathrm{AUC})} \text { oral bioavailability calculated } \\
\text { using dose-corrected AUC values, } R_{\mathrm{ac}} \text { accumulation ratio, } t_{1 / 2} \text { half-life, } C_{\mathrm{R}} \\
\text { renal excretory clearance, } f_{\mathrm{e}-\mathrm{u}} \text { fraction of dose excreted into urine, } F_{(\mathrm{C} \text { (Cum.Ae- }} \\
\text { u) oral bioavailability calculated using dose-corrected Cum. } A_{\mathrm{e}-\mathrm{U}} \text { values }\end{array}$} \\
\hline
\end{tabular}

As shown in Fig. 5, four ginkgolides, each at $100 \mu \mathrm{mol} / \mathrm{L}$ in trilactone form, completely inhibited PAF-16-induced rabbit platelet aggregation. Based on their $\mathrm{IC}_{50}$ (Table 5), ginkgolide $\mathrm{B}$ exhibited the most potent inhibition, followed by ginkgolides $A$ and $C$; the inhibition potency of ginkgolide $J$ was weak. Reduced inhibition potencies were observed for ginkgolides $A, B$, and $C$ after incubating these compounds in isotonic phosphate-buffered saline $(\mathrm{pH}$ 7.4) for $3 \mathrm{~h}$, and such potencies reduced further after incubation in human plasma $(\mathrm{pH} \mathrm{7.4)}$ for $3 \mathrm{~h}$ (Table 5). These results suggested that carboxylation of ginkgolides $A, B$, and $C$ could reduce their PAF antagonistic activities. Unlike these ginkgolides, bilobalide (in trilactone form) and the flavonoids, each at $100 \mu \mathrm{mol} / \mathrm{L}$, showed negligible or no inhibition of platelet aggregation (Fig. 5).

\section{DISCUSSION}

Terpene lactones are a class of bioactive constituents that are believed to be responsible for cardiovascular and cerebrovascular actions of preparations of G. biloba leaf extract. Here, plasma pharmacokinetics and renal excretion of terpene lactones were systematically characterized in human subjects who received oral YinXing-TongZhi tablet or i.v. ShuXueNing. After dosing YinXingTongZhi tablet, circulating ginkgolides exhibit significantly different oral bioavailability, i.e., ginkgolide $B>$ ginkgolide $A$ » ginkgolide $J>$ ginkgolide $C$, albeit their structural similarity. An earlier Caco-2 cellbased study suggests that these ginkgolides exhibit different (low to intermediate) rates of membrane permeation and that the intestinal efflux transporters MDR-1 and MRP2 weakly mediate cellular efflux of ginkgolides $A$ and $B$ in vitro but do not act on ginkgolides $C$ and $J$ [20]. Given that enterohepatic metabolism [20] and hepatobiliary excretion in humans (as discussed below) are most likely limited for these ginkgolides, the inter-compound differences in oral bioavailability is associated mainly with membrane permeability-dependent intestinal absorption. Membrane permeability of ginkgolide $B$ was found to be influenced by $\mathrm{pH}$-dependent carboxylation of the compound and to be preferably absorbed in the duodenum [42]. Similar scenarios are expected to occur with the other ginkgolides. This may partially explain the significant differences in intestinal absorption among ginkgolides $\mathrm{A}, \mathrm{B}, \mathrm{C}$, and J. It is worth mentioning that apparent $F_{(A \cup C)}$ values of ginkgolides $A$ and $B$ in human subjects 


\begin{tabular}{|c|c|c|c|c|c|c|}
\hline \multirow[t]{2}{*}{ Transporter } & \multicolumn{6}{|l|}{ Net transport ratio } \\
\hline & Probe substrate & Ginkgolide A & Ginkgolide B & Ginkgolide C & Ginkgolide J & Bilobalide \\
\hline OAT1 & 56.7 (Para-aminohippuric acid) & 1.3 & 1.2 & 0.9 & 1.7 & 2.2 \\
\hline OAT2 & 31.4 (Prostaglandin $F_{2 \alpha}$ ) & 1.2 & 1.6 & 1.6 & 1.9 & 1.2 \\
\hline OAT3 & 7.5 (Estrone-3-sulfate) & 1.2 & 1.2 & 1.9 & 2.6 & 1.0 \\
\hline ОСТ2 & 8.5 (Tetraethylammonium) & 1.2 & 1.2 & 1.0 & 0.8 & 1.2 \\
\hline OCTN1 & 3.8 (Tetraethylammonium) & 1.1 & 1.3 & 1.9 & 1.4 & 1.2 \\
\hline MATE1 & 31.8 (Tetraethylammonium) & 1.0 & 1.5 & 2.3 & 1.2 & 1.3 \\
\hline
\end{tabular}
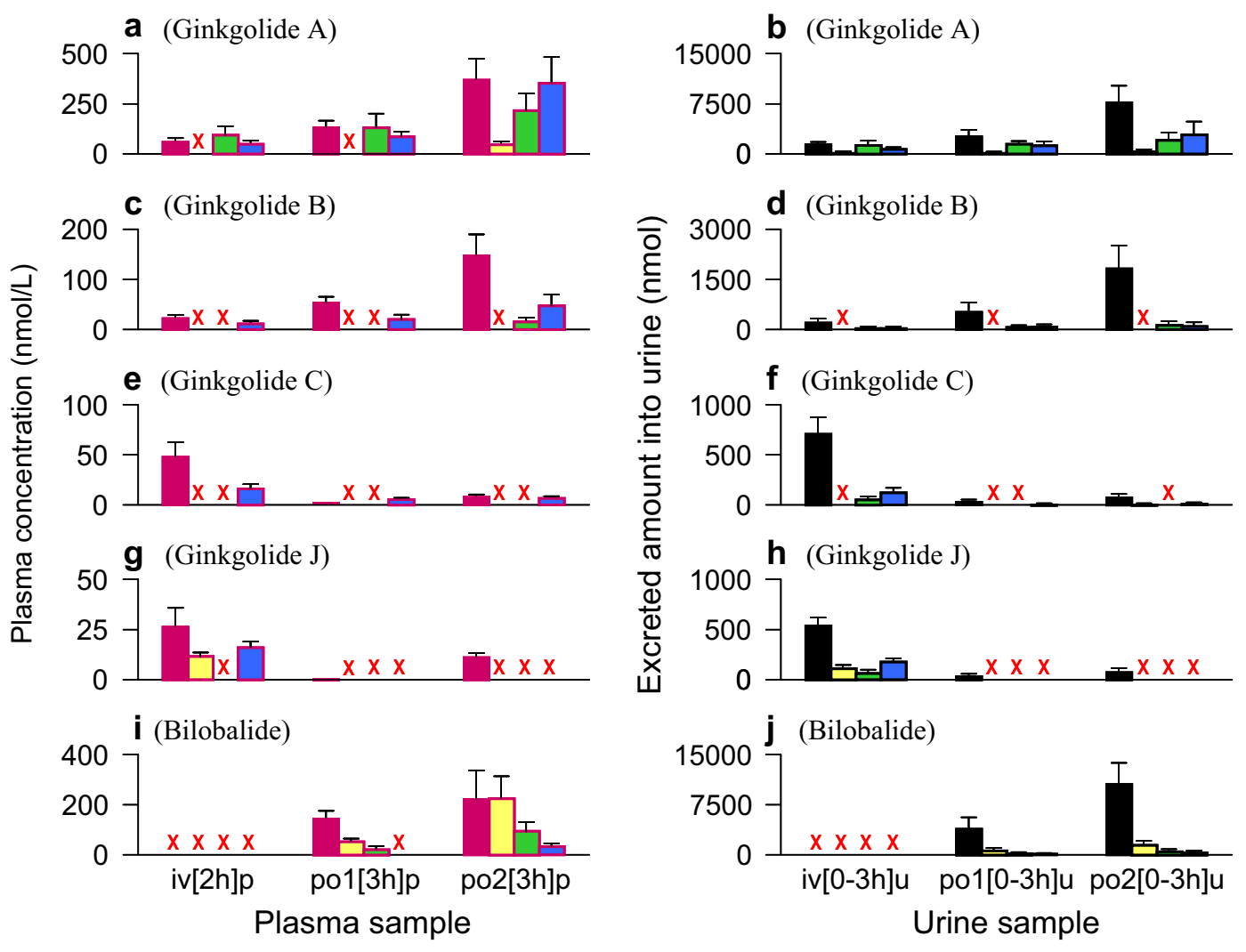

Fig. 3 Trilactone and monocarboxylate forms of ginkgo terpene lactones detected in plasma (a, $\mathbf{c}, \mathbf{e}, \mathbf{g}$, and $\mathbf{i})$ and urine samples $(\mathbf{b}$, $\mathbf{d}$, $\mathbf{f}$, $\mathbf{h}$, and j) of human subjects who received a 2 -h i.v. infusion of ShuXueNing or a p.o. dose of YinXing-TongZhi tablet. Iv[2 h]p, po1[3 h]p, and po2[3 h]p stand for plasma samples at $2 \mathrm{~h}$ after starting a 2-h i.v. infusion of ShuXueNing at $20 \mathrm{~mL} /$ person, $3 \mathrm{~h}$ after a p.o. dose of YinXing-TongZhi tablet at 3 tablets/person, and $3 \mathrm{~h}$ after a p.o. dose of YinXing-TongZhi tablet at 9 tablets/person, respectively. Iv[0-3 h] u, po1 [0-3 h]u, and po2[0-3 h] stand for urine samples at 0-3 h after starting a 2-h i.v. infusion of ShuXueNing at $20 \mathrm{~mL} /$ person, after a p.o. dose of YinXing-TongZhi tablet at 3 tablets/person, and after a p.o. dose of YinXing-TongZhi tablet at 9 tablets/person, respectively. The red symbol x denotes "not detected". Red and black bars are used to show trilactone forms of ginkgo terpene lactones in plasma and in urine, respectively, while light yellow, light green, and light blue bars are used to show their three monocarboxylate isomers in plasma and in urine

(mostly >100\%) were significantly higher than the respective values in rats $(52-58 \%$ and $33-40 \%$, respectively [21]). These differences between humans and rats is due to, at least in part, the interspecies differences in hepatobiliary excretion in presystemic elimination of ginkgolides $A$ and $B$ in human subjects (YinXingTongZhi tablet: $f_{\mathrm{e}-\mathrm{U}}, 63-80 \%$ and $58-69 \%$, respectively; ShuXueNing: $f_{\mathrm{e}-\mathrm{U}}, 94$ and $74 \%$, respectively) and in rats (GBE50: $f_{\mathrm{e}-\mathrm{U}} / f_{\mathrm{e}-\mathrm{B},}, 40 \% / 15 \%$ and $28 \% / 24 \%$, respectively; ShuXueNing: $f_{\mathrm{e}-\mathrm{U}} / f_{\mathrm{e}-\mathrm{B}}, 29 \% / 18 \%$ and $28 \% / 34 \%$, respectively [21]). Hepatobiliary excretion of drugs is related to their molecular mass, with significant interspecies differences, i.e., $>475 \mathrm{Da}$ favors excretion into bile in humans and
$>400 \mathrm{Da}$, in rats [43]. The molecular masses of ginkgolides $\mathrm{A}$ and $\mathrm{B}$ are 408 and $424 \mathrm{Da}$, respectively. The very high apparent $F_{(\mathrm{AUC})}$ of ginkgolides $A$ and $B$ (mostly $>100 \%$ ) in human subjects probably reflect the compounds' flip-flop pharmacokinetic characteristics, albeit their terminal $t_{1 / 2}$ for YinXing-TongZhi tablet being only around 1.5 times as long as the respective $t_{1 / 2}$ for ShuXueNing. Different from the $F_{(\mathrm{AUC})}$ of ginkgolides $\mathrm{A}$ and $\mathrm{B}$, the respective $F_{\text {(Cum. }}$ Ae-U) are also high but lower than 100\% (Tables 2 and 3). Like ginkgolides $A$ and $B$, bilobalide has an intermediate rate of membrane permeation. Bilobalide is not affected by the intestinal efflux transporters and is poorly excreted into bile in rats $[20,21]$. 


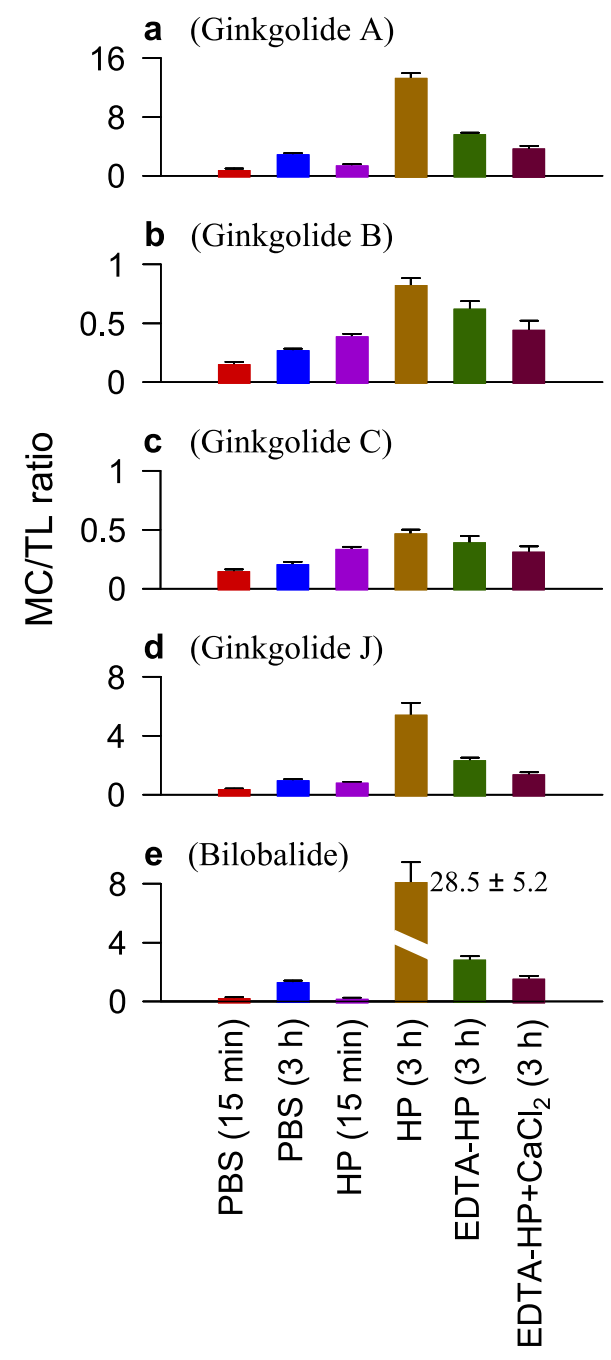

Incubation condition

Fig. 4 Comparative carboxylation of ginkgo terpene lactones in isotonic phosphate-buffered saline, blank human plasma, and EDTApretreated human plasma and influence of $\mathrm{CaCl}_{2}$ on EDTA treatment. The concentrations of EDTA and $\mathrm{CaCl}_{2}$ were 5 and $10 \mathrm{mmol} / \mathrm{L}$, respectively. MC/TL ratio total monocarboxylate form-totrilactone form ratio

Comparison of dose-corrected plasma $\mathrm{AUC}_{0-\infty}$ of bilobalide with those of ginkgolides $A$ and $B$ in human subjects suggests that bilobalide has high oral bioavailability, which is probably lower than those of the two ginkgolides.

In addition to intestinal absorption, in vivo reach and elimination route governing systemic exposure are the other two important pharmacokinetic characteristics for a drug to exert its in vivo pharmacodynamic effects. Factors that determine the drug's in vivo reach include its delivery to the tissues of drug response through blood flow, tissue membrane permeability and influences of transporters, and binding in both plasma and tissue. Despite their membrane permeability associated with large intercompound differences in intestinal absorption, the $V_{S S}$ values of ginkgolides A, B, C, and J differ to a relatively limited extent. All of the $V_{\mathrm{SS}}$ are around the human volume of total body water (i.e., the sum of the intracellular fluid, interstitial fluid, and plasma volumes), suggesting that, after dosing, these ginkgolides distribute evenly in various body fluids and tissues, except for the barriered tissues (such as the brain [21]). Perfusion-rate limitation prevails for these ginkgo compounds, which likely reach well both extracellular and intracellular targets; the cell membranes in most tissues present essentially no barrier to their in vivo reach. Given their distribution characteristics and limited binding in plasma, binding of these ginkgolides to tissue components is also expected to be limited. Accordingly, binding competition between plasma and tissue likely has a limited influence on in vivo reach of these ginkgolides. In vivo reach of bilobalide is similar to that of the ginkgolides, based on its $V_{S S} / F$, ratio of dose-corrected $\mathrm{AUC}_{0-\infty}$ to that of ginkgolide $\mathrm{A}$, and $f_{\mathrm{u}}$ in humans, as well as on its pharmacokinetic characteristics (including tissue distribution) observed in rats [21]. Regarding the elimination route in humans, ginkgolides $A, B, C$, and $J$ are cleared from the systemic circulation mainly through glomerularfiltration-based renal excretion, based on their $f_{\mathrm{e}-U}$ and $\mathrm{CL}_{\mathrm{R}} /$ $\left(G F R \times f_{\mathrm{u}}\right)$ values and on the negative results of the renal transporters' actions. These elimination characteristics suggest that these ginkgolides have low likelihood to be victims of conventional metabolism-mediated and transporter-mediated drug interactions. However, alteration of renal blood flow (due to co-administration of haemodynamics-improving drugs, such as furosemide, dopamine, and dobutamine) and renal diseases (and associated dialysis treatment) are likely to result in altered renal clearance of and, in turn, altered levels of systemic exposure to these ginkgolides. Although glomerular-filtration-based renal excretion is a major elimination route for bilobalide, other elimination routes for this terpene lactone warrant future investigation.

Due to their trilactone structural feature, ginkgolides and bilobalide can undergo pH-dependent carboxylation leading to opening of the lactone rings [30, 31]. Consistent with the observation by other investigators [33-35], both the trilactone forms of ginkgolides $\mathrm{A}, \mathrm{B}, \mathrm{C}$, and $\mathrm{J}$ and bilobalide and their carboxylated forms occur in isotonic phosphate-buffered saline $(\mathrm{pH}$ 7.4) and human plasma ( $\mathrm{pH} 7.4$ ); formation of monocarboxylates prevails for opening the compounds' lactone rings. However, the compounds' MC/TL ratios for plasma are significantly higher than such ratios for the saline. PON1 in human plasma might be responsible for the increased ratios, because of positive inhibitory effects of EDTA treatment on the lactone ring opening and negative antagonistic actions of added $\mathrm{CaCl}_{2}$ on the EDTA effects. PON1 is a calcium-dependent esterase synthesized in the liver and associated with high density lipoprotein in blood. This esterase may play an important physiological role in lipid metabolism and protection against the development of atherosclerosis [32]. In addition to toxic organophosphates, many botanic lactone compounds are hydrolyzed by PON1 [44-46]. Different from other esterases in blood, PON1, and PON3 can be inactivated by calcium chelation. The activity of PON3 inhibited by EDTA can be restored by adding calcium ion, while such restore of PON1 activity is notably less effective by adding calcium ion [47]. Given that the level of PON1 in blood differs among individuals and is modulated by disease state, dietary, life-style, and environmental factors [48], an additional pharmacokinetic study is planned to investigate the influence of PON1 on carboxylation of ginkgo terpene lactones in patients. Ginkgolides are the only circulating ginkgo compounds that exhibit PAF antagonistic activities. The PAF antagonistic activities of ginkgolides $A, B$, and $C$ are reduced, by the lactone ring opening, as the $\mathrm{MC} / \mathrm{TL}$ ratios increase. These findings suggest that the $\mathrm{pH}$ dependent and PON1-dependent lactone carboxylation should be considered in future evaluation of pharmacodynamic activities of ginkgo terpene lactones and in investigation of associated pharmacokinetic/pharmacodynamic correlations.

In this investigation, terpene lactones were characterized with respect to their pharmacokinetics in healthy human subjects who received G. biloba leaf extract formulation, i.e., YinXing-TongZhi tablet or ShuXueNing. In summary, p.o. administration of YinXingTongZhi tablet provides high levels of systemic exposure to ginkgolides A and B and bilobalide, while i.v. administration of ShuXueNing provides high exposure levels of ginkgolides $C$ and J. 


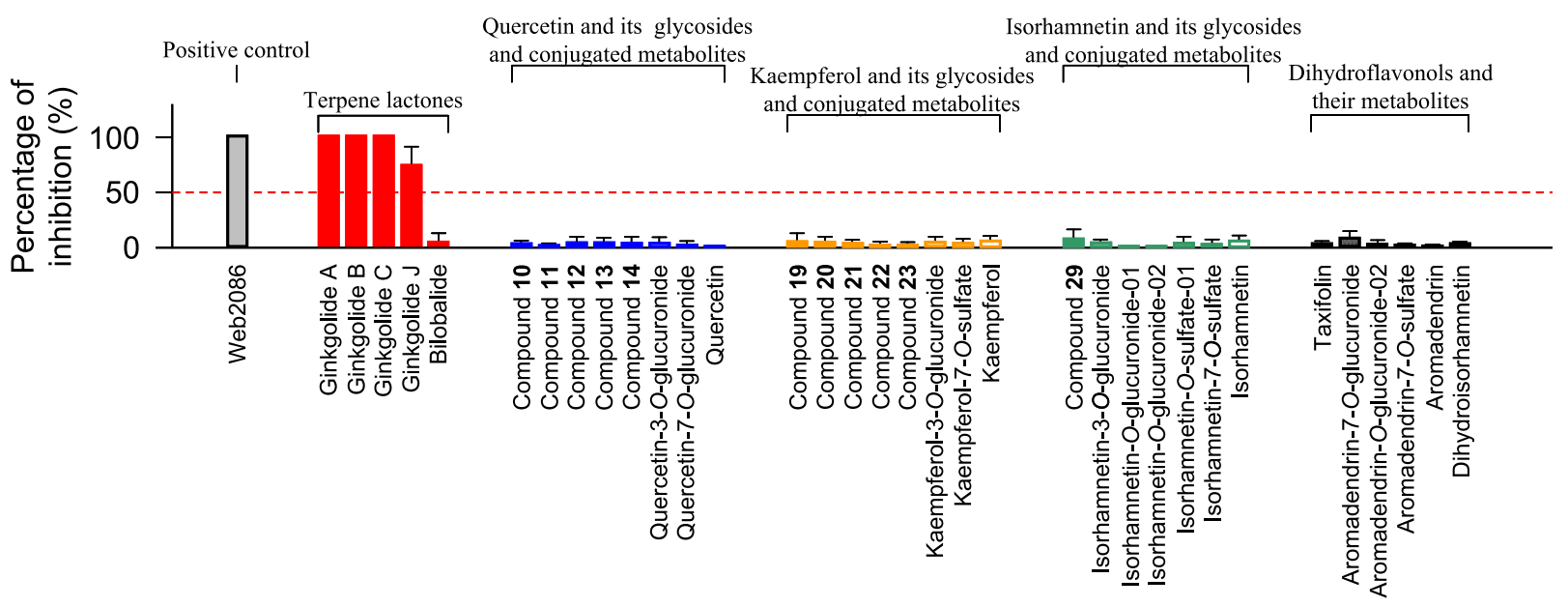

Compound 10: 3-O-[ $\alpha$-L-rhamnopyranosyl $\left.\left(1^{\prime \prime} \rightarrow 2^{\prime \prime}\right)\right]\left[\alpha\right.$-L-rhamnopyranosyl $\left.\left(1^{\prime \prime} \rightarrow 6^{\prime \prime}\right)\right]-\beta$-D-glucopyranosyl-quercetin

Compound 11: 3-O-[6-O-coumaroyl- $\beta$-D-glucopyranosyl- $\left.\left(1^{\prime \prime} \rightarrow 2^{\prime \prime}\right)\right]-\alpha$-L-rhamnopyranosyl-quercetin

Compound 12: 3-O-[ $\alpha$-L-rhamnopyranosyl $\left.\left(1^{\prime \prime} \rightarrow 6^{\prime \prime}\right)\right]-\beta$-D-glucopyranosyl-quercetin

Compound 13: 3-O-[ $\beta$-D-glucopyranosyl- $\left.\left(1^{\prime \prime} \rightarrow 2^{\prime \prime}\right)\right]-\alpha$-L-rhamnopyranosyl-quercetin

Compound 14: 3-O-glucopyranosyl-quercetin

Compound 19: 3-O-[ $\alpha$-L-rhamnopyranosyl $\left.\left(1^{\prime \prime} \rightarrow 2^{\prime \prime}\right)\right]\left[\alpha\right.$-L-rhamnopyranosyl $\left.\left(1^{\prime \prime} \rightarrow 6^{\prime \prime}\right)\right]-\beta$-D-glucopyranosyl-kaempferol

Compound 20: 3-O-[6-O-coumaroyl- $\beta$-D-glucopyranosyl- $\left.\left(1^{\prime \prime} \rightarrow 2^{\prime \prime}\right)\right]$ - $\alpha$-L-rhamnopyranosyl-kaempferol

Compound 21: 3-O-[ $\alpha$-L-rhamnopyranosyl $\left.\left(1^{\prime \prime} \rightarrow 6^{\prime \prime}\right)\right]-\beta$-D-glucopyranosyl-kaempferol

Compound 22: 3-O-[ $\beta$-D-glucopyranosyl- $\left.\left(1^{\prime \prime} \rightarrow 2^{\prime \prime}\right)\right]-\alpha$-L-rhamnopyranosyl-kaempferol

Compound 23: 3-O-glucopyranosyl-kaempferol

Compound 29: 3-O-[ $\alpha$-L-rhamnopyranosyl $\left.\left(1^{\prime \prime} \rightarrow 6^{\prime \prime}\right)\right]-\beta$-D-glucopyranosyl-isorhamnetin

Fig. 5 Percentage inhibition of PAF-16-induced rabbit platelet aggregation by ginkgo terpene lactones and flavonoids at $100 \mu \mathrm{mol} / \mathrm{L}$. Glycosides of ginkgo flavonoids are the major circulating forms after intravenously dosing ShuXueNing in human subjects, while aglycone conjugates (mainly glucuronides and sulfates) of ginkgo flavonoids are the major circulating forms after orally dosing YinXing-TongZhi tablet; the detailed human pharmacokinetics and disposition of ginkgo flavonoids are pending publication elsewhere. WEB2086 (CAS number, 105219-56-5) is a positive PAF antagonist

Table 5. Inhibitory effects of ginkgolides on PAF-16-induced rabbit platelet aggregation

Terpene lactone $\mathrm{IC}_{50}(\mu \mathrm{mol} / \mathrm{L})$

\begin{tabular}{|c|c|c|c|}
\hline & $\begin{array}{l}\text { Ginkgolide in trilactone } \\
\text { form }\end{array}$ & $\begin{array}{l}\text { Ginkgolide pre-incubated in isotonic phosphate- } \\
\text { buffered saline ( } \mathrm{pH} 7.4) \text { for } 3 \mathrm{~h}\end{array}$ & $\begin{array}{l}\text { Ginkgolide pre-incubated in fresh human } \\
\text { plasma }(\mathrm{pH} \text { 7.4) for } 3 \mathrm{~h}\end{array}$ \\
\hline Ginkgolide A & $2.88 \pm 0.80$ & $4.25 \pm 0.19$ & $20.2 \pm 1.3$ \\
\hline Ginkgolide C & $8.66 \pm 0.36$ & $13.2 \pm 0.7$ & $46.0 \pm 5.1$ \\
\hline Ginkgolide J & $42.9 \pm 0.6$ & - & - \\
\hline
\end{tabular}

The significant inter-compound differences in oral bioavailability can be attributed to the difference in intestinal absorption among these ginkgo terpene lactones. Ginkgolides A and B appear to have flipflop pharmacokinetic characteristics after dosing YinXing-TongZhi tablet. Low plasma concentrations of bilobalide after dosing ShuXueNing result from its low content level in the dosed injection. Compared with their intestinal absorption, in vivo reach of the terpene lactones differ to a relatively limited extent; these ginkgo compounds appear to reach well both extracellular and intracellular therapeutic targets. Glomerular-filtration-based renal excretion is the predominant elimination route, in humans, for the ginkgolides, unbound fractions of which are $45-92 \%$ in plasma. Such renal excretion is a major elimination route for bilobalide; other elimination routes for this ginkgo compound warrant further investigation. Terpene lactones circulated in forms of trilactone and monocarboxylate. Influence of such carboxylation should be considered in investigation of pharmacodynamic activities of terpene lactones.

\section{ACKNOWLEDGEMENTS}

This work was funded by grants from the Science \& Technology Commission of Shanghai Municipality (13DZ1970200), the National Science \& Technology Major Project of China "Key New Drug Creation and Manufacturing Program" (2009ZX09304-002 and 2017ZX09301012006), the National Science Foundation of China for Distinguished Young Scholars (30925044) and the Strategic Priority Research Program of the Chinese Academy of Sciences (XDA12050306).

\section{AUTHOR CONTRIBUTIONS}

Participated in research design: $\mathrm{CL}, \mathrm{LL}, \mathrm{Y}-\mathrm{hH}$. Conducted experiments: LL, X-wL, J-IY, WN, W-wJ, QW, X-nD, F-qW, F-fD, C-cZ, Y-fL, FX. Performed data analysis: $C L, L L, Q G, X-w L$. Wrote or contributed to the writing of the manuscript: $C L, L L$, OEO, X-wL.

\section{ADDITIONAL INFORMATION}

The online version of this article (https://doi.org/10.1038/s41401-018-0086-7) contains supplementary material, which is available to authorized users. 
Competing interests: The authors declare no competing interests.

\section{REFERENCES}

1. Drieu K, Jaggy H. History, development and constituents of EGb761. In: van Beek TA, editor. Ginkgo biloba. Armsterdam: Harwood Academic Publishers; 2000. p. 267-77.

2. DeFeudis FV. A brief history of EGb 761 and its therapeutic uses. Pharmacopsychiatry. 2003;36:S2-7.

3. Strømgaard K, Nakanishi K. Chemistry and biology of terpene trilactones from Ginkgo biloba. Angew Chem Int Ed. 2004;43:1640-58.

4. Blumenthal M. The $A B C$ clinical guide to herbs. New York: Thieme; 2003. pp. 185-200.

5. van Beek TA, Montoro P. Chemical analysis and quality control of Ginkgo biloba leaves, extracts, and phytopharmaceuticals. J Chromatogr A. 2009;1216:2002-32.

6. Gu J-H, Ge J-B, Li M, Wu F, Zhang W, Qin Z-H. Inhibition of NF-KB activation is associated with anti-inflammatory and anti-apoptotic effects of Ginkgolide B in a mouse model of cerebral ischemia/reperfusion injury. Eur J Pharm Sci. 2012;47:652-60.

7. Zhao Q-P, Gao C-Y, Cui Z-F. Ginkgolide A reduces inflammatory response in highglucose-stimulated human umbilical vein endothelial cells through STAT3mediated pathway. Int Immunopharmacol. 2015;25:242-8.

8. Zhang S, Chen B-D, Wu W, Bao L, Qi R-M. Ginkgolide B reduces inflammatory protein expression in oxidized low-density lipoprotein-stimulated human vascular endothelial cells. J Cardiovasc Pharmacol. 2011;57:721-7.

9. Zhou W, Chai H, Courson A, Lin PH, Lumsden AB, Yao Q-Z, et al. Ginkgolide A attenuates homocysteine-induced endothelial dysfunction in porcine coronary arteries. J Vasc Surg. 2006;44:853-62.

10. Maerz S, Liu C-H, Guo W, Zhu Y-Z. Anti-ischaemic effects of bilobalide on neonatal rat cardiomyocytes and the involvement of the platelet-activating factor receptor. Biosci Rep. 2011;31:439-47.

11. Cho HJ, Nam KS. Inhibitory effect of ginkgolide $B$ on platelet aggregation in a cAMP- and cGMP-dependent manner by activated MMP-9. J Biochem Mol Biol. 2007;40:678-83.

12. Cheung $\mathrm{F}$, Siow $\mathrm{YL}, \mathrm{O} \mathrm{K}$. Inhibition by ginkgolides and bilobalide of the production of nitric oxide in macrophages (THP-1) but not in endothelial cells (HUVEC). Biochem Pharmacol. 2001;61:503-10.

13. Priyanka A, Nisha VM, Anusree SS, Raghu KG. Bilobalide attenuates hypoxia induced oxidative stress, inflammation, and mitochondrial dysfunctions in 3T3-L1 adipocytes via its antioxidant potential. Free Radic Res. 2014;48:1206-17.

14. Lachachi H, Plantavid M, Simon MF, Chap H, Braquet P, Douste-Blazy L. Inhibition of transmembrane movement and metabolism of platelet activating factor (PAFacether) by a specific antagonist, BN 52021. Biochem Biophys Res Commun. 1985;132:460-6.

15. Lamant V, Mauco G, Braquet P, Chap H, Douste-Blazy L. Inhibition of the metabolism of platelet activating factor (PAF-acether) by three specific antagonists from Ginkgo biloba. Biochem Pharmacol. 1987;36:2749-52.

16. Montrucchio G, Alloatti G, Camussi G. Role of platelet-activating factor in cardiovascular pathophysiology. Physiol Rev. 2000;80:1669-99.

17. Yoo H, Ku SK, Baek YD, Bae JS. Anti-inflammatory effects of rutin on HMGB1induced inflammatory responses in vitro and in vivo. Inflamm Res. 2014;63:197-206.

18. Choi JS, Kang SW, Li J, Kim JL, Bae JY, Kim DS, et al. Blockade of oxidized LDLtriggered endothelial apoptosis by quercetin and rutin through differential signaling pathways involving JAK2. J Agric Food Chem. 2009;57:2079-86.

19. Afana'ev IB, Dorozhko Al, Brodskii AV, Kostyuk VA, Potapovitch Al. Chelating and free radiacal scavenging mechanisms of inhibitory action of rutin and quercetin in lipid peroxidation. Biochem Pharmacol. 1989;38:1763-9.

20. Li L, Zhao Y-S, Du F-F, Yang J-L, Xu F, Niu W, et al. Intestinal absorption and presystemic elimination of various chemical constituents present in GBE50 extract, a standardized extract of Ginkgo biloba leaves. Curr Drug Metab. 2012;13:494-509.

21. Chen F, Li L, Xu F, Sun Y, Du F-F, Ma X-T, et al. Systemic and cerebral exposure to and pharmacokinetics of flavonols and terpene lactones after dosing standardized Ginkgo biloba leaf extracts to rats via different routes of administration. $\mathrm{Br} J$ Pharmacol. 2013;170:440-57.

22. Sousa T, Paterson R, Moore V, Carlsson A, Abrahamsson B, Basit AW. The gastrointestinal microbiota as a site for the biotransformation of drugs. Int J Pharm. 2008;363:1-25.

23. Mahmood I, Sahajwalla C. Interspecies scaling of biliary excreted drugs. J Pharm Sci. 2002;91:1908-14.
24. Mauri $P$, Simonetti $P$, Gardana $C$, Minoggio $M$, Morazzoni $P$, Bombardelli $E$, et al. Liquid chromatography/atmospheric pressure chemical ionization mass spectrometry of terpene lactones in plasma of volunteers dosed with Ginkgo biloba L. extracts. Rapid Commun Mass Spectrom. 2001;15:929-34.

25. Woelkart K, Feizlmayr E, Dittrich P, Beubler E, Pinl F, Suter A, et al. Pharmacokinetics of bilobalide, ginkgolide $A$ and $B$ after administration of three different Ginkgo biloba L. preparations in humans. Phytother Res. 2010;24:445-50.

26. Drago F, Floriddia ML, Cro M, Giuffrida S. Pharmacokinetics and bioavailability of a Ginkgo biloba extract. J Ocul Pharmacol Ther. 2002;18:197-202.

27. Wang FM, Yao TW, Zeng S. Determination of quercetin and kaempferol in human urine after orally administered tablet of Ginkgo biloba extract by HPLC. J Pharm Biomed Anal. 2003;33:317-21.

28. Ude C, Schubert-Zsilavecz M, Wurglics M. Ginkgo biloba extracts: a review of the pharmacokinetics of the active ingredients. Clin Pharmacokinet. 2013;52:727-49.

29. Maclennan KM, Darlington CL, Smith PF. The CNS effects of Ginkgo biloba extracts and ginkgolide B. Prog Neurobiol. 2002;67:235-57.

30. Zekri $O$, Boudeville $P$, Genay $P$, Perly $B$, Braquet $P$, Jouenne $P$, et al. Ionization constants of ginkgolide $B$ in aqueous solution. Anal Chem. 1996;68:2598-604.

31. Lan K, Li X-J, Du G, Xu L. Characterizations of the hydrolyzed products of ginkgolide $A$ and ginkgolide $B$ by liquid chromatography coupled with mass spectrometry. J Pharm Biomed Anal. 2016;118:113-22.

32. Draganov DI, La DuBN. Pharmacogenetics of paraoxonases: a brief review. Naunyn Schmiede Arch Pharmacol. 2004;369:78-88.

33. Wang D-L, Peng D-Y, Tao X-H, Cao Y, Chen W-D, Liang Y, et al. The pharmacokinetics and conversion of the lactone to the carboxylate forms of ginkgolide $B$ in rat plasma. J Asian Nat Prod Res. 2013;15:337-43.

34. Liu X-G, Qi L-W, Fan Z-Y, Dong X, Guo R-Z, Lou F-C, et al. Accurate analysis of ginkgolides and their hydrolyzed metabolites by analytical supercritical fluid chromatography hybrid tandem mass spectrometry. J Chromatogr A. 2015;1388:251-8.

35. Li X-J, Wang Y-Q, Yang J, Fan X, Wang L, Yang K, et al. Semi-quantitative determination of monocarboxylate forms of ginkgolide $B$ in plasma by UPLC-MS. Anal Bioanal Chem. 2015;407:4121-9.

36. Guo B, Li C, Wang G-J, Chen L-S. Rapid and direct measurement of free concentrations of highly protein-bound fluoxetine and its metabolite norfluoxetine in plasma. Rapid Commun Mass Spectrom. 2006;20:39-47.

37. Davies B, Morris T. Physiological parameters in laboratory animals and humans. Pharm Res. 1993;10:1093-5.

38. Jia W-W, Du F-F, Liu X-W, Jiang R-R, Xu F, Yang J-L, et al. Renal tubular secretion of tanshinol: molecular mechanisms, impact on its systemic exposure, and propensity for dose-related nephrotoxicity and for renal herb-drug interactions. Drug Metab Dispos. 2015;43:669-78.

39. Zhao Y, Sun Y, Li C. Simultaneous determination of ginkgo flavonoids and terpenoids in plasma: ammonium formate in LC mobile phase enhancing electrospray ionization efficiency and capacity. J Am Soc Mass Spectrom. 2008;19:445-9.

40. Feng B, LaPerle JL, Chang G, Varma MV. Renal clearance in drug discovery and development: molecular descriptors, drug transporters and disease state. Expert Opin Drug Metab Toxicol. 2010;6:939-52.

41. Varma MV, Feng B, Obach RS, Troutman MD, Chupka J, Miller HR, et al. Physicochemical determinants of human renal clearence. J Med Chem. 2009;52:4844-52.

42. Lv H, Wang G-J, Wu X-L, Xie L, Huang C-R, Li H, et al. Transport characteristics of ginkgolide $\mathrm{B}$ by Caco-2 cells and examination of ginkgolide $\mathrm{B}$ oral absorption potential using rat in situ intestinal loop method. Int J Pharm. 2008;351:31-5

43. Yang X-N, Gandhi YA, Duignan DR, Morris ME. Prediction of biliary excretion in rats and humans using molecular weight and quantitative structurepharmacokinetic relationships. AAPS J. 2009;11:511-25.

44. Gao Q, Zhang Y-F, Wo S, Zuo Z. Hydrolysis is the dominating in vivo metabolism pathway for arctigenin: identification of novel metabolites of arctigenin by LC/ MS/MS after oral administration in rats. Planta Med. 2013;79:471-9.

45. Hioki T, Fukami T, Nakajima M, Yokoi T. Human paraoxonase 1 is the enzyme responsible for pilocarpine hydrolysis. Drug Metab Dispos. 2011;39:1345-52.

46. Draganov DI, Teiber JF, Speelman A, Osawa Y, Sunahara R, La Du BN. Human paraoxonases (PON1, PON2, and PON3) are lactonases with overlapping and distinct substrate specificities. J Lipid Res. 2005;46:1239-47.

47. Pla A, Rodrigo L, Hernández AF, Gil F, Lopez O. Effect of metal ions and calcium on purified PON1 and PON3 from rat liver. Chem Biol Interact. 2007;167:63-70.

48. Costa LG, Cole TB, Jarvik GP, Furlong CE. Functional genomic of the paraoxonase (PON1) polymorphisms: effects on pesticide sensitivity, cardiovascular disease, and drug metabolism. Annu Rev Med. 2003;54:371-92. 